\title{
ANÁLISE DE CONSUMO NUMA UNIDADE HOTELEIRA NO ALGARVE - PORTUGAL, COM O RECURSO DE FERRAMENTAS DE BUSINESS INTELLIGENCE
}

\author{
ANALYSIS OF CONSUMPTION IN A HOTEL IN THE ALGARVE - PORTUGAL, USING BUSINESS \\ INTELLIGENCE TOOLS
}

\section{ANÁLISIS DE CONSUMO EN UN HOTEL DEL ALGARVE - PORTUGAL, UTILIZANDO HERRAMIENTAS DE BUSINESS INTELLIGENCE}

Miguel da Luz Guerreiro Mestre em Direção e Gestão Hoteleira pela Universidade do Algarve, Portugal miguel.guerreiro.92@gmail.com

\begin{abstract}
Marisol B. Correia
Professora Adjunta na Escola Superior de Gestão, Hotelaria e Turismo (ESGHT) da Universidade do Algarve (UAlg) Membro-Colaborador do CEG-IST do Instituto Superior Técnico da Universidade de Lisboa

Doutora em Engenharia Eletrónica e Computação pela Universidade do Algarve Mestre em Engenharia Eletrotécnica e de Computadores pela Universidade de Lisboa, Portugal mcorreia@ualg.pt
\end{abstract}

Carlos M. R. Sousa Professor Adjunto na Escola Superior de Gestão, Hotelaria e Turismo (ESGHT) da Universidade do Algarve (UAlg) Doutor em Ciências Económicas e Empresariais pela Universidade de Huelva, Espanha Mestre em Ciências Económicas e Empresariais pela Universidade do Algarve, Portugal cmsousa@ualg.pt

Data de Submissão: 04/07/2016 Data de Aceitação: 05/07/2017

RESUMO: O presente artigo tem como objetivo dotar o setor da hotelaria com dados relevantes para a previsão de vendas, receitas, ocupação e encomendas de stock, com base na análise de uma amostra de clientes de uma unidade hoteleira de quatro estrelas localizada no Algarve - Portugal, constituída pelas quinze nacionalidades com maior taxa de ocupação durante o ano de 2014. Desta forma, pretende-se aferir as preferências dos hóspedes relativamente a consumos nos estabelecimentos de restauração e bebidas, de acordo com a tipologia de quarto, regime de alojamento e agência de viagem/operador turístico, examinando igualmente, utilizando estatística univariada, as despesas com o alojamento e os consumos realizados no ano de 2014. A partir da análise e da interpretação dos resultados obtidos, foi possível verificar que, apesar de Portugal ser a nacionalidade com maior número de hóspedes na unidade em 2014, os portugueses despenderam menos do que os germânicos no que toca aos consumos nos estabelecimentos de restauração e bebidas. Todavia, os hóspedes portugueses foram os clientes mais assíduos do Restaurante $\mathrm{X}$ no último quadrimestre do ano e terão, efetivamente, efetuado maiores despesas com o alojamento e os respetivos regimes em todo o ano civil.

PALAVRAS-CHAVE: Business Intelligence, Consumos, Data Warehouse, Hotelaria.

ABSTRACT: This article reports on a study carried out with relevant data concerning stock, occupancy and sales forecasts and estimates of revenue for the hospitality industry, analyzing a sample of guests of a four-star hotel located in the Algarve, Portugal, which comprises the fifteen nationalities with the highest occupancy rate during 2014. The aim was to assess the guests' preferences according to their consumption in the hotel's restaurants and bars, their room type, their accommodation type, and their travel agency/tour operator, whilst examining the univariate data on the accommodation and consumption expenses in 2014. Based on an analysis and interpretation of the results, it was found that although Portuguese was the nationality with the highest registered number of hotel guests in 2014, the Portuguese spent less than the German on food and beverages in the establishments. On the other hand, the Portuguese were the most regular customers to Restaurant X during the third quarter of the year, and may have spent larger amounts of money on accommodation throughout the calendar year. 
KEYWORDS: Business Intelligence, Consumption, Data Warehouse, Hospitality.

RESUMEN: El presente artículo tiene como objetivo proporcionar al sector de la hotelería los datos relevantes para la previsión de ventas, ingresos, ocupación y pedidos de stock, con base en el análisis de una muestra de clientes de un hotel de 4 estrellas localizado en el Algarve $\mathrm{Q}$ Portugal, constituida por las quince nacionalidades con mayor tasa de ocupación durante el año 2014. De esta forma, se pretenden evaluar las preferencias de los huéspedes respecto al consumo en los establecimientos de alimentación y bebidas, de acuerdo con el tipo de habitación, el régimen de alojamiento y la agencia de viaje/operador turístico, examinando también, a través de estadística univariada, los gastos con el alojamiento y los consumos realizados en el año 2014. A partir del análisis e interpretación de los resultados obtenidos, se ha podido verificar que, aunque Portugal sea la nacionalidad con mayor número de huéspedes en el hotel en 2014, los portugueses han gastado menos que los alemanes en los establecimientos de alimentación y bebidas. Sin embargo, los huéspedes portugueses han sido los clientes más asiduos en el Restaurant $X$ en el último cuatrimestre del año y, en efecto, habrán efectuado mayores gastos con el alojamiento y los regímenes en todo el año civil.

PALABRAS CLAVE: Business Intelligence; Consumos; Data Warehouse; Hotelería.

INTRODUÇÃO

tualmente, as Tecnologias de Informação (TI) desempenham um
papel cada vez mais crucial no seio das empresas pertencentes
aos vários setores da economia, entre os quais se inclui a indústria hoteleira. As TI são fundamentais para a gestão dos recursos humanos, gestão financeira e contabilística, gestão de clientes e fornecedores e gestão de stocks e da produção. Além dos referidos processos operacionais, estes sistemas geram uma quantidade considerável de informação bastante útil para a organização de uma empresa (Oliveira, 2010).

Além do mais, as TI visam sustentar as atividades de gestão de conhecimento e têm sido consideradas como ferramentas indispensáveis no que toca à inovação, à inteligência, à aprendizagem e à criatividade organizacional nas instituições do período pós-industrial. Nos últimos anos, as aplicações das Tecnologias de Informação têm dado origem a novas práticas organizacionais, tais como o comércio eletrónico, a gestão do relacionamento dos clientes, também conhecida por CRM (Customer Relationship Management), ou a SCM (Supply Chain Management) (Turban, Sharda, \& Delen, 2011).

Por outro lado, são os denominados sistemas de Business Intelligence (BI), compostos pelas tecnologias Data Warehouse (DW), On-Line Analytical Processing (OLAP) e Data Mining, que "utilizam os dados disponíveis nas organizações para disponibilizar informação relevante para a tomada de decisão" e ampliam as capacidades de memória e raciocínio dos colaboradores de uma empresa (Santos \& Ramos, 2006, p. 2). 
O presente artigo tem como propósito realizar uma análise aprofundada das preferências dos hóspedes de uma unidade hoteleira, utilizando estatística univariada associada aos consumos nos estabelecimentos de restauração e bebidas da unidade, aos regimes de alojamento, aos montantes pagos pela estadia, à tipologia de quarto e à entidade intermediária pela qual efetuaram a reserva, por meio do cruzamento dos dados anteriormente referidos com as nacionalidades dos hóspedes com recurso a ferramentas de BI para determinar as suas preferências. De facto, as unidades hoteleiras recolhem e armazenam grandes quantidades de dados relativos à sua atividade operacional os quais se prendem com as interações dos seus clientes durante as estádias, embora, devido a lacunas dos Property Management System (PMS) na consolidação e na sumarização da informação para a criação de indicadores de gestão, não utilizem plenamente esta informação se não recorrerem a ferramentas de análise, como de BI, para extrair tendências e padrões que auxiliem nos processos de tomada de decisão.

Este artigo começa por abordar a importância do papel desempenhado pelas TI e BI nas empresas, seguindo-se a caracterização e a descrição das funcionalidades do DW, a distinção entre um DW e uma Base de Dados (BD) Transacional, a descrição do conceito de Modelação Multidimensional e as respetivas representações gráficas, a enumeração das técnicas de OLAP e as técnicas de Data Mining. Posteriormente, segue-se a explicação da metodologia utilizada no estudo, a análise e a discussão dos resultados obtidos por meio das relações criadas entre os dados por intermédio das ferramentas Microsoft Powerpivot e Powerview, as considerações finais do artigo e as referências bibliográficas.

\section{REVISÃO DA LITERATURA}

\section{BUSINESS INTELLIGENCE}

O sistema de BI pode ser definido como "uma ferramenta que permite aos gestores de negócios uma análise inteligente da infinidade de dados gerados pelos seus diversos sistemas e processos. Como o próprio nome indica, as soluções de BI são adotadas para trazer inteligência ao negócio de uma companhia" (Curcio, 2011). No fundo, é um sistema de suporte que faz chegar a informação adequada aos gestores na altura certa. O BI compreende 
ferramentas e sistemas orientados para recolher e analisar dados de maneira organizada e estratégica para a empresa. É fulcral para auxiliar as empresas que procuram compreender o comportamento dos clientes e, ao mesmo tempo, ficar cientes dos potenciais riscos para os seus negócios. Tal só é conseguido por meio de BI, nomeadamente no que toca a traçar o perfil dos seus clientes, realizar pesquisas e segmentação do mercado e elaborar análises estatísticas e inventários (Curcio, 2011; Chen, Chiang, \& Storey, 2012).

Além do mais, o BI acarreta uma série de vantagens para as empresas, tais como a redução de custos administrativos e de gastos relativos a softwares e a processo de avaliação de projetos; a maior rapidez no que ao Retorno sobre Investimento (ROI) diz respeito; o maior rigor na correção dos dados; a maior segurança da informação; consistência da informação, independentemente das bases de dados onde se encontra dispersada; e, por último, o alinhamento de informações estratégicas e operacionais (Curcio, 2011).

Um sistema de BI tem a capacidade de fornecer dados relacionados com clientes, recursos humanos, contabilidade, entre outros aspetos, dependendo do tamanho das empresas. Contudo, segundo Marcos Chomen, diretor regional da Cognos no Brasil, "as necessidades de saber, por exemplo, quem vende mais, qual produto dá maior margem de lucro e outras informações desse tipo, são comuns às empresas de todos os portes" (Curcio, 2011).

Ao longo dos anos, o BI tem vindo a ser alvo de uma evolução notória, tendo as suas funcionalidades sido bastante aprimoradas. Anteriormente, segundo Câmara, da Infobuild, o BI "era uma ferramenta de controlo e planeamento a médio e longo prazo, que emitia relatórios anuais e semestrais." Atualmente, já se pode afirmar que se tornou uma enorme aplicação de análise preditiva, dotada de uma capacidade de reunir e examinar todos os dados recolhidos pelas companhias por intermédio de sistemas de gestão empresarial, ferramentas de gestão da cadeia de provisões SCM e, em particular, das soluções de gestão de CRM (Curcio, 2011).

Com efeito, é possível concluir que os sistemas de $B /$ desempenham um papel relevante em relação ao aumento: i) da inteligência coletiva da entidade, já que facilitam a construção do conhecimento indispensável para o planeamento e a implementação de soluções para as ameaças da sobrevivência e da prosperidade 
da instituição; ii) da capacidade de aprendizagem por parte da organização, visto que contribuem para a adaptação dos seus membros a uma prática de trabalho em contínua renovação; e iii) da criatividade organizacional, na medida em que contribuem para a criação de novos serviços, produtos ou ideologias favoráveis à acomodação, aos desafios e às oportunidades intrínsecos e extrínsecos (Santos \& Ramos, 2006, pp. 2-3).

\section{DATA WAREHOUSE}

O DW "é um conjunto de dados orientado a assuntos, integrados, variável ao longo do tempo e não-volátil para apoiar o processo de tomada de decisão dos gestores" (Inmon W. H., 2002, p. 31). Por outras palavras, o DW consiste essencialmente num depósito de dados o qual permite o armazenamento de informação relevante para a tomada de decisão das organizações. O DW é orientado por assunto, uma vez que os dados são separados e organizados por assunto, dependendo do tema que os gestores das empresas pretendam analisar e interpretar. Não está direcionado para as tarefas que fazem parte do dia a dia da empresa, mas oferece uma perspetiva bastante simples e resumida de determinado assunto, eliminando todos os dados não relevantes. Outra das grandes vantagens que aporta é o facto de ser catalogado temporalmente, isto é, armazena dados respeitantes a um período de tempo, que pode variar entre 5 a 10 anos. Desta forma, o DW concede ao utilizador uma perspetiva histórica da informação, em vez de sistemas operacionais, que acumulam dados históricos limitados a um período de tempo bastante mais curto (Turban, Sharda, \& Delen, 2011).

Por outro lado, o DW também se caracteriza pela sua ausência de volatilidade, isto é, não é permitida a eliminação ou a modificação dos dados assim que sejam carregados. A técnica de integração de dados, que consolida a consistência dos mesmos, pode ser definida como "o processo pelo qual as características dos dados-fonte são modificadas para permitir a sua inserção num Data Warehouse" (Santos \& Ramos, 2006, p. 64). Por outras palavras, os dados devem ser tratados e organizados antes de serem inseridos num DW, de forma a permitir uma análise mais simples.

Segundo (Kimball \& Ross, 2013, pp. 3-4), o sistema de DW deve possuir os seguintes requerimentos: i) "tornar a informação de fácil acesso", sendo que, 
para tal, "o sistema de DW/BI deve ser compreensível", "os dados devem ser intuitivos e claros" e as ferramentas e as aplicações de BI terão de ser "de fácil e de simples utilização" de forma a simplificar o trabalho do utilizador; ii) "apresentar a informação de forma atempada", ou seja, a conversão dos dados tem de ser efetuada numa questão de segundos, minutos ou horas, e "de forma consistente", visto que os dados devem ser agregados a partir de um leque variado de fontes e apenas lançados quando forem considerados "aptos" para análise; iii) "ter capacidade de adaptação à mudança", porque "as necessidades dos utilizadores, as condições empresariais, os dados e as tecnologias" estão sempre em constante atualização, o que poderá invalidar os dados e as aplicações de BI.

Adicionalmente, deverá iv) "ser um alicerce seguro para proteção dos ativos de informação", isto é, saber manter a confidencialidade dos dados, impedindo, para tal, o seu acesso a utilizadores que, por exemplo, não pertençam à organização; v)"servir como uma base de sustentação fidedigna e credível para o aperfeiçoamento do processo de tomada de decisão"; vi) o sistema DW/BI deve ser aceito e considerado útil pelas organizações, uma vez que a utilização deste sistema ainda é opcional no mundo empresarial, independentemente de ser um processo "simples e rápido" e da excelente qualidade das ferramentas, aplicações e plataformas.

\section{COMPARAÇÃO DATA WAREHOUSE VS BASE DE DADOS} TRANSACIONAL

Em primeiro lugar, há que referir que uma BD Transacional contém todas as informações operacionais da empresa de uma forma bastante pormenorizada e, por vezes, desorganizada, não pondo de parte dados de quase nula relevância e que pouco acrescentam à análise realizada pelos gestores. Numa BD Transacional, o utilizador é confrontado com uma estrutura bastante complexa e de difícil compreensão, devido ao elevado número de tabelas e de associações e à inexistência de preocupação com a organização e a disponibilização dos dados para o mesmo. Por outro lado, numa DW, os dados provenientes de BD Transacionais e de outros sistemas operacionais sãotransformados em diagramas mais pequenosorganizados segundo as normas de negócio da organização e existe uma preocupação notória com a apresentação dos dados ao utilizador (Oliveira, 2010). 
EnquantoasBDTransacionaissuportam OLTP(On-line TransactionalProcessing), que está vocacionado para a automatização do processamento de dados do dia a dia, o registro de dados redundantes e a modificação de informação já presente nos sistemas, as DW admitem OLAP, ferramentas que lidam com análises de dados multidimensionais (Chaudhuri, Dayal, \& Narasayya, 2011).

As BD Transacionais são mais utilizadas por técnicos informáticos ou funcionários especializados para tarefas rotineiras e operacionais, ao passo que os $D W$, como referido anteriormente, estão mais direcionados para os gestores ou administradores das companhias para análise dos dados mais relevantes e indispensáveis para as decisões estratégicas. Há igualmente a salientar que as DW são, regra geral, mantidas separadamente das BD Transacionais das organizações.

A utilização das DW em vez das BD Transacionais nas organizações tornase mais vantajosa, na medida em que provoca uma redução do tempo que os gestores necessitam para obtenção das informações necessárias aos seus processos decisórios, enquanto permite reunir informação dispersa por uma enorme variedade de bases de dados e plataformas distintas de uma forma mais fácil e eficiente. Além disso, as DW empresariais são projetadas para ocupar centenas de gigabytes ou terabytes, tendo tendência, por essa razão, a possuir uma capacidade de maior magnitude do que as BD Transacionais. Os dados históricos, sumariados e consolidados das DW são mais importantes do que o enorme e confuso número de entradas individuais detalhadas geradas pelas BD Transacionais (Rodrigues \& Ferreira, [s.d.], pp. 5-6).

\section{MODELAÇÃO MULTIDIMENSIONAL}

A modelação multidimensional pode ser descrita como uma técnica de simplificação de consultas da informação armazenada no DW sob diferentes perspetivas, sendo, por essa razão, representada normalmente por cubos. É uma metodologia que visa proporcionar uma fácil interação com o utilizador final e um elevado desempenho no processamento de queries/consultas.

De forma a facilitar a interação com o utilizador, as tabelas das bases de dados deverão estar desnormalizadas, isto é, todos os atributos presentes nas tabelas, independentemente de serem ou não relevantes para a análise e 
consequente resultado final, deverão ser apresentados. É muito vulgar que os mesmos dados apareçam repetidos em diversas tabelas.

O DW pode ser representado por três tipologias de esquemas: o esquema em estrela, em floco de neve ou em constelação de factos. Tais representações são o resultado da modelação multidimensional. Esta modelação consiste na composição de uma estrutura de base de dados de compreensão e manipulação acessível para o utilizador. Para tal acontecer, a modelação recorre a um dos três esquemas: estrela, floco de neve ou constelação de factos.

O esquema em estrela é a representação mais comum do DW. A estrutura deste esquema visa facilitar a consulta dos dados e conferir maior velocidade de exploração de dados, sendo constituída por uma única tabela de factos, que surge no centro do esquema, e pelas tabelas de dimensões interligadas a esta primeira (Oliveira, 2010).

A tabela de factos "integra um conjunto de atributos numéricos (factos) e um conjunto de chaves estrangeiras que relacionam a tabela de factos com as diversas dimensões que lhe estão associadas" (Santos \& Ramos, 2006, p. 67). Estas dimensões estão contidas nas denominadas tabelas de dimensão, as quais contêm dados geralmente separados em diferentes níveis hierárquicos e que determinam possíveis relações com a tabela de factos.

Como é possível observar na Figura 2.1, a tabela Vendas corresponde à tabela de factos. Desta forma, podem estabelecer-se relações com qualquer das várias tabelas de dimensão: Produtos, Clientes, Tempo, Lojas e Vendedores, sendo conveniente salientar a ausência de normalização das tabelas de dimensões, ou seja, a presença de dados redundantes, embora estas possam inclusivamente comportar hierarquias. Por exemplo, na Dimensão Tempo, o componente Dia da Semana poderia estar dividido em segunda, terça, quarta, quinta, sexta, sábado e domingo.

No esquema em floco de neve, embora seja inclusivamente constituída por uma tabela de factos e várias tabelas de dimensões, a estrutura deixa de ser regular, podendo, assim, exibir um outline diferente nos ramos. Apesar de tanto o esquema em estrela como o esquema em floco de neve apresentarem semelhanças ao nível das interrogações que são capazes de comportar e do conteúdo de dados, este último caracteriza-se pela complexidade da sua estrutura (Santos \& Ramos, 2006, pp. 68-69). A grande desvantagem deste esquema prende-se com a frequente 
dificuldade de interpretação/compreensão da mesma, dada a sua imagem intrincada, enquanto se verifica uma diminuição da qualidade do desempenho no que toca ao processamento de interrogações (Han, Kamber, \& Pei, 2012, p. 140).

Todavia, o esquema em floco de neve detém duas vantagens em relação ao esquema mencionado anteriormente. Verifica-se uma normalização das dimensões, evitando-se, assim, a redundância de informação e a estrutura de cada uma das suas dimensões está bem mais explícita e hierarquizada no esquema em floco de neve do que no conjunto não estruturado do esquema em estrela. Como se pode observar na Figura 2.2, a tabela de dimensão Lojas está relacionada com duas tabelas de subdimensão, Estados e Regiões, simplificando, assim, a sua identificação, enquanto no esquema em estrela (Figura 2.1), os atributos Região e Estado encontram-se na mesma tabela da Dimensão Lojas (Moody \& Kortink, 2003, pp. 9-10).

Figura 2.1 - Esquema em Estrela

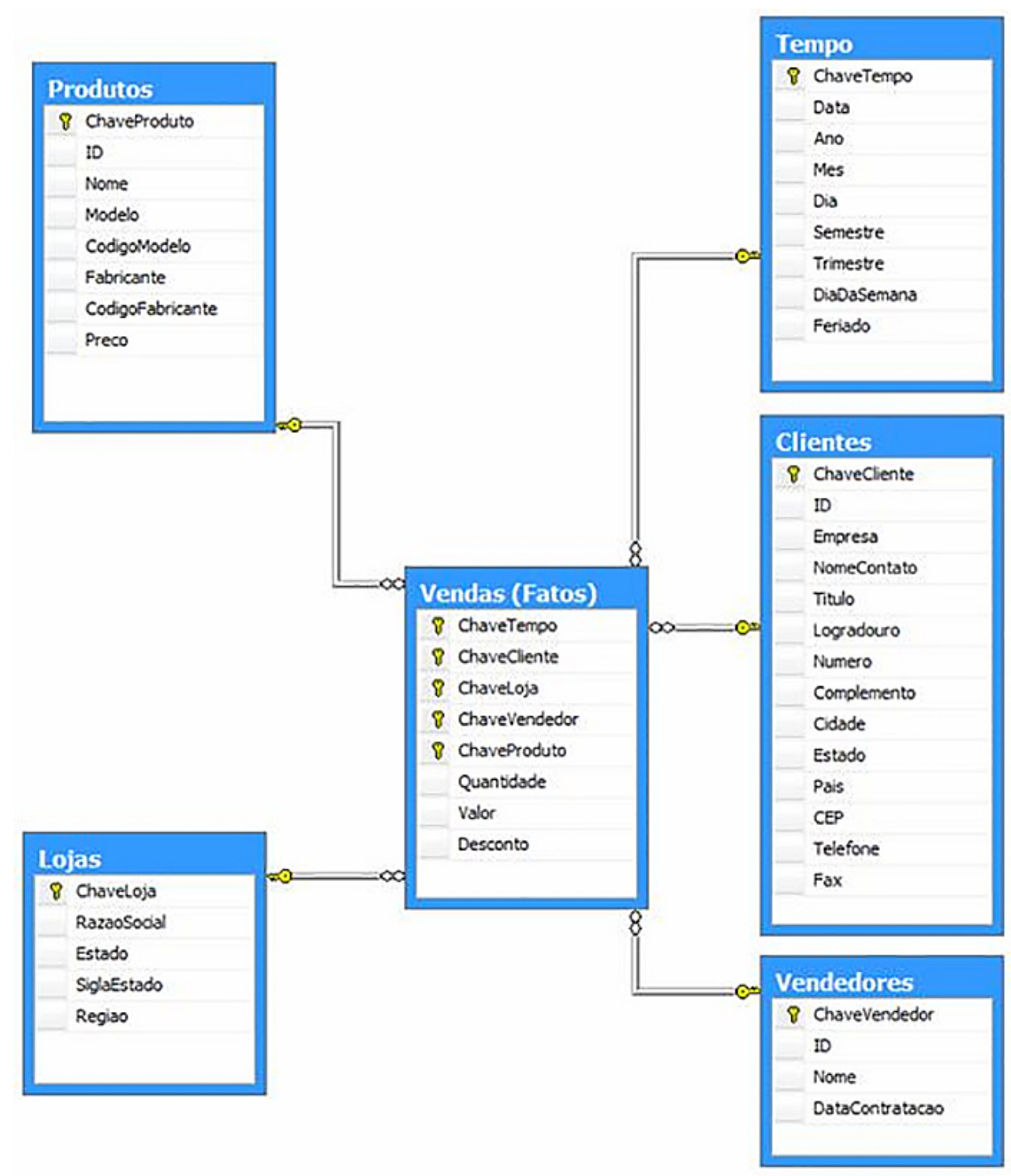

Fonte: (Nardi, 2007). 
Quanto ao esquema em constelação de factos, este permite integrar mais do que uma tabela de factos, estando estes interligados por tabelas de dimensões partilhadas entre si, isto é, o esquema em constelação de factos é como um esquema em estrela em duplicado, embora também possa assumir uma forma em triplicado ou quadruplicado, e por aí adiante.

Figura 2.2 - Esquema em Floco de Neve

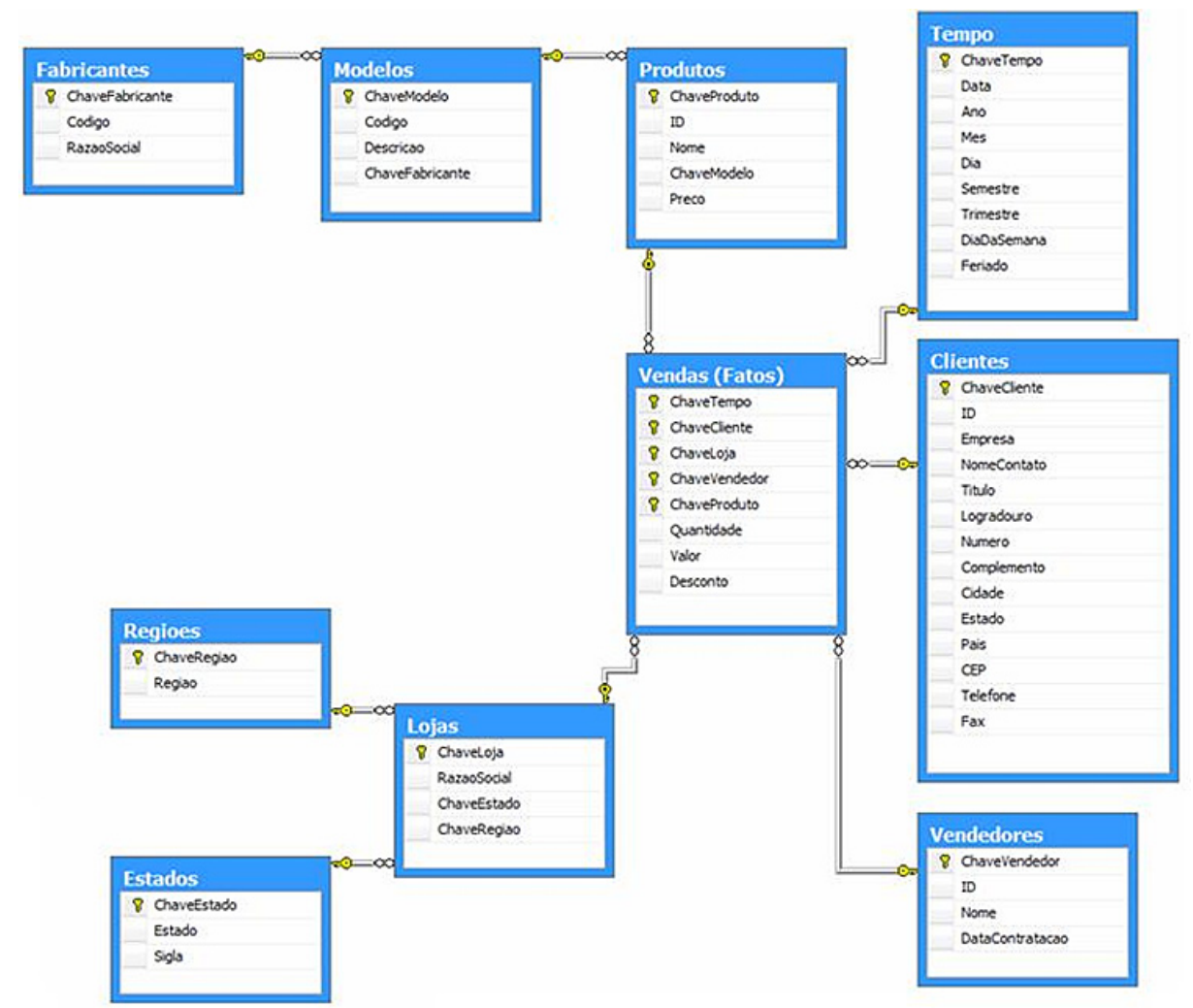

Fonte: (Nardi, 2007).

OLAP (ON-LINE ANALYTICAL PROCESSING)

As ferramentas OLAP e Data Mining são duas tecnologias de grande utilidade relativamente à análise da informação armazenada nos DW. A OLAP Dpermite criar cubos para analisar a informação sob diferentes perspetivas $\square$ (Santos \& Ramos, 2006, p. 72). Os cubos constituem um método de análise dos factos presentes nas tabelas de factos sob os diferentes prismas que as dimensões englobadas na modelação oferecem.

Os cubos multidimensionais podem sofrer várias transformações por meio de técnicas de manipulação, entre as quais se destacam as seguintes (Santos \& Ramos, 2006, pp. 74-75): 
- Drill-down, que fornece uma perspetiva mais detalhada dos dados, permitindo, deste modo, a transição da visualização de dados generalizados para dados mais pormenorizados. Por exemplo, esta técnica possibilita a transição da navegação dos dados anuais das despesas de uma empresa para dados semestrais, trimestrais e assim sucessivamente.

- Roll-up, que tem uma função contrária ao drill-down, visto que reúne todos os dados visualizados no cubo por meio de hierarquias. A agregação vai aumentando de dimensão à medida que a análise é repetida. Tomando o exemplo anterior, a análise passa de dados mensais das despesas para dados trimestrais, semestrais e anuais.

- Slice and dice, que ajuda a selecionar apenas uma parte da informação que se pretende analisar. "O corte (slice) permite selecionar um subconjunto de dados do cubo ( ). A redução (dice) permite definir um subcubo para o qual podem ser especificados critérios de seleção para duas ou mais dimensões".

- Pivot ou rotação, que "permite rodar os eixos de visualização dos dados", possibilitando assim uma análise sob uma diferente perspetiva dos mesmos dados.

\section{DATA MINING}

O Data Mining consiste "na procura de relacionamentos, padrões ou modelos que estão implícitos nos dados armazenados nas grandes bases de dados" (Santos \& Ramos, 2006, p. 103). A classificação, a estimativa e a previsão são as três técnicas de Data Mining direta, que visa "utilizar os dados disponíveis de forma a construir um modelo de descrição de uma variável de interesse em relação aos restantes dados disponíveis" (Berry \& Linoff, 2000, p. 8).

METODOLOGIA

O presente estudo consiste numa análise aprofundada dos hábitos de consumo de uma unidade hoteleira consoante o país de origem dos hóspedes, assim como a sua preferência pela tipologia de quarto, entidade intermediária 
(agências ou operadores turísticos (OT)), regimes de alojamento e estatística univariada associada aos montantes pagos no alojamento e nos consumos efetuados nos estabelecimentos comerciais do hotel. Desde já, há que mencionar que, por uma questão de confidencialidade, foram omitidos os nomes da unidade hoteleira e dos seus estabelecimentos, que foram substituídos por Restaurante X, Bar X e Bar Y, bem como dos dados alvos de análise neste artigo. Foi igualmente garantida a confidencialidade dos dados de cada hóspede durante o desenrolar do processo, uma vez que dados como os nomes ou os números do Bilhete de Identidade (B.I.) não foram considerados nesta análise.

De forma a poder concretizar este estudo, foi necessário o recurso ao Enterprise Resource Planning (ERP) ligado ao PMS da cadeia do referido hotel, a partir do qual se realizou a emissão dos relatórios mensais ou trimestrais, acerca dos consumos nos diferentes pontos de venda do hotel: Bar X, Bar Y e Restaurante X. Estes dados eram obtidos a partir do Point of Sales (POS) instalado em cada ponto de venda, que estava diretamente ligado ao PMS do hotel. No entanto, para poder confrontar todos estes consumos com as nacionalidades dos hóspedes, era necessário recorrer ao Rooming List, um relatório que contém uma variedade imensa de dados detalhados acerca de todos os hóspedes que passaram pelo hotel, desde o nome do cliente à tipologia de quarto da reserva ou até à data em que este realizou o check-in e o check-out.

De referir que as reservas analisadas foram efetuadas, na sua maioria, em nome individual e não em grupo, uma vez que é difícil discernir se todos os membros de um grupo teriam a mesma nacionalidade, o que concederia à análise uma margem de erro bastante mais elevada, tornando-a, dessa forma, mais inexata.

Para estabelecer relações entre dados, utilizaram-se ferramentas associadas ao $B I$, nomeadamente o Microsoft Powerview e Powerpivot, disponíveis no Microsoft Excel 2013.

Como se pode observar na Figura 3.1, o esquema representativo criado é o esquema emfloco deneve, visto que só existe uma tabela defactos(Fact_Reservas), que se encontra ligada por todas as outras tabelas de dimensão, estando uma destas ligada a uma tabela de subdimensão (DimNacionalidade). 
De modo a produzir este esquema, procedeu-se primeiramente à criação da tabela de factos Fact_Reservas, a partir de um conjunto de várias tabelas de consumos dos estabelecimentos da unidade e dos dados do relatório Rooming List. Em seguida, deu-se início à elaboração das tabelas de dimensão DimPontodeVenda, DimConsumos, DimCliente, DimNacionalidade, DimTipoQuarto, DimEntidade e DimTempo.

Figura 3.1 - Esquema Base para Análise

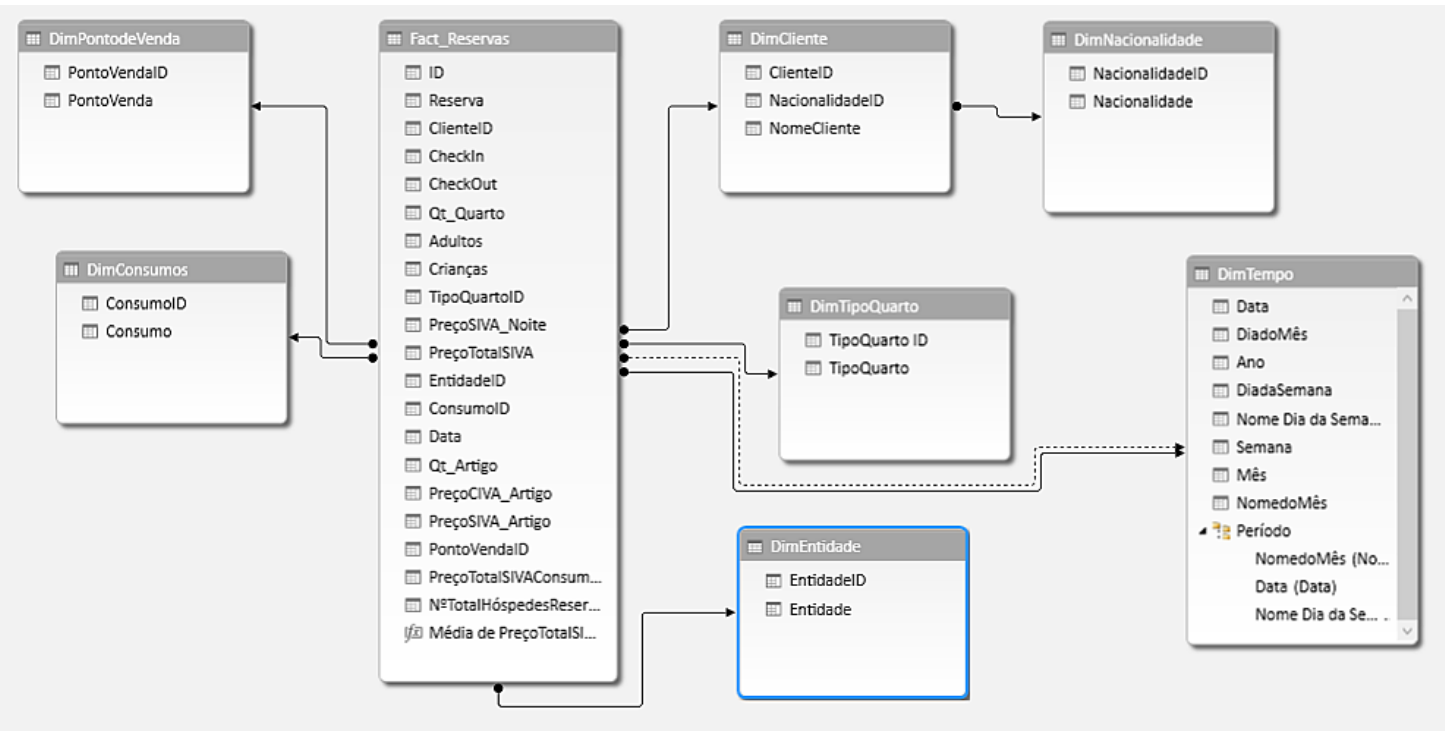

Fonte: Elaboração própria.

\section{RESULTADOS DA ANÁLISE}

De forma a poder desenvolver este estudo, o primeiro passo consistiu na aferição do número total de hóspedes. Tendo em consideração que o Rooming List (está parcialmente incorporado na tabela de Fact_Reservas, mas representa melhor, no seu todo, a realidade da ocupação do que a tabela de factos) estava organizado por número de reservas e não de hóspedes, foi necessário recorrer à soma do número de adultos e crianças por reserva.

O número total de hóspedes a visitarem a unidade no ano civil de 2014 foi de 32919. Contudo, devido à eliminação de duplicados, o número transitou para 32360, o que perfaz um total de aproximadamente $98 \%$ do universo total de hóspedes em 2014. A partir dos dados obtidos no Rooming List, foi elaborado o Gráfico 3.1 com o número de hóspedes correspondente a cada nacionalidade para poder utilizá-la na análise aos restantes dados. 
Como se pode observar no Gráfico 3.1, Portugal e Alemanha são as nacionalidades mais representadas, perfazendo conjuntamente cerca de $74 \%$ do total do número de hóspedes da unidade. A Espanha, o UK, os EUA, a Polónia, a França, a Holanda e o Brasil representam conjuntamente valores próximos de 19\%, o que significa que apenas $7 \%$ são completadas pelas outras 79 nações. São apenas os 15 países destacados nesta tabela, ou seja, cerca de 93\% do número de hóspedes em 2014, que irão ser alvo de um estudo mais aprofundado em diferentes períodos do ano, uma vez que as outras nações, tendo contribuído individualmente com menos de 100 visitantes, revelariam valores pouco interessantes para a análise.

O número total de hóspedes que realizaram consumos nos estabelecimentos da unidade foram de 21692, ou seja, apenas cerca de $67 \%$ da amostra analisada. Estima-se que os hóspedes da unidade tenham efetuado gastos, em relação ao alojamento e aos consumos nos estabelecimentos da unidade, num valor médio aproximado de $416 €$ por estadia.

Gráfico 3.1 - No de Hóspedes por Nacionalidade

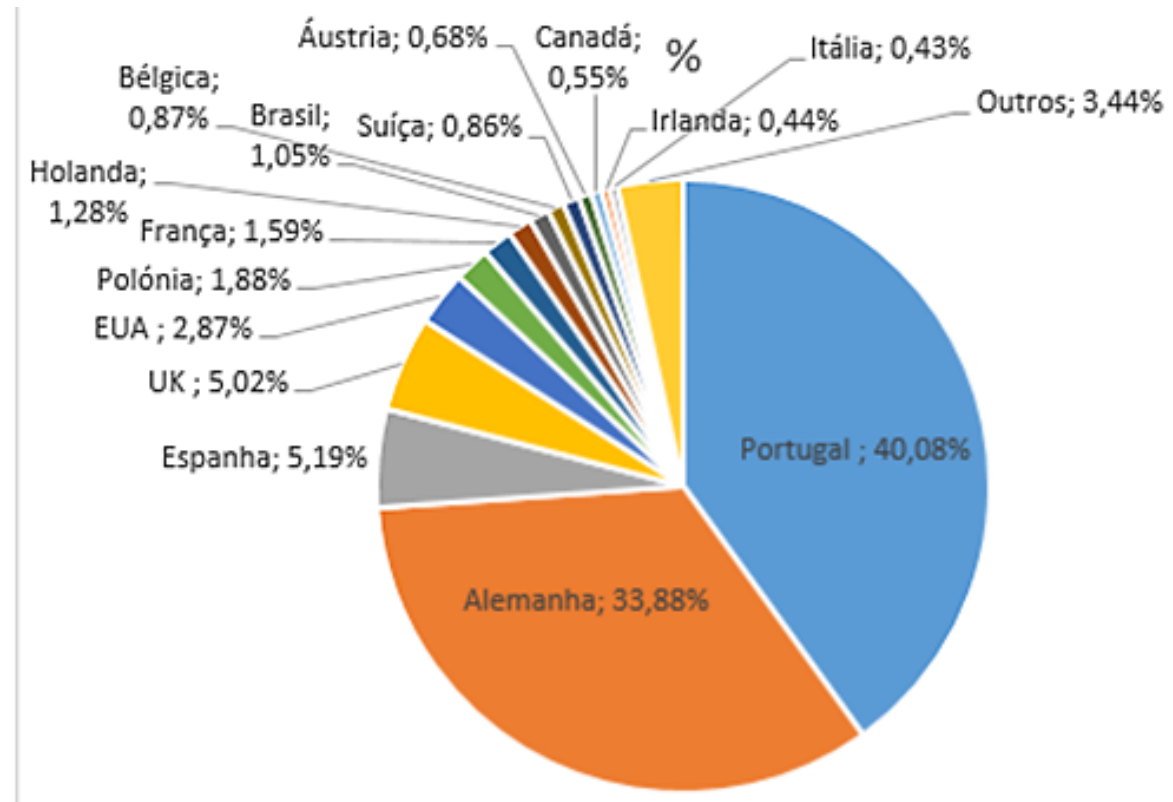

Fonte: Elaboração própria.

Na Figura 3.2 é visível a predominância dos hóspedes germânicos em relação aos demais entre os meses de janeiro e abril, perfazendo $52,77 \%$ do total das 15 nacionalidades. Portugal é logicamente a $2^{a}$ nação mais bem representada, com $31,51 \%$, ou seja, cerca de $84,28 \%$ dos hóspedes que efetuaram consumos entre janeiro e abril tinham nacionalidade alemã ou portuguesa. 
Figura 3.2 - $\mathrm{N}^{\circ}$ de Hóspedes com Consumos no $1^{\circ}$ Quadrimestre

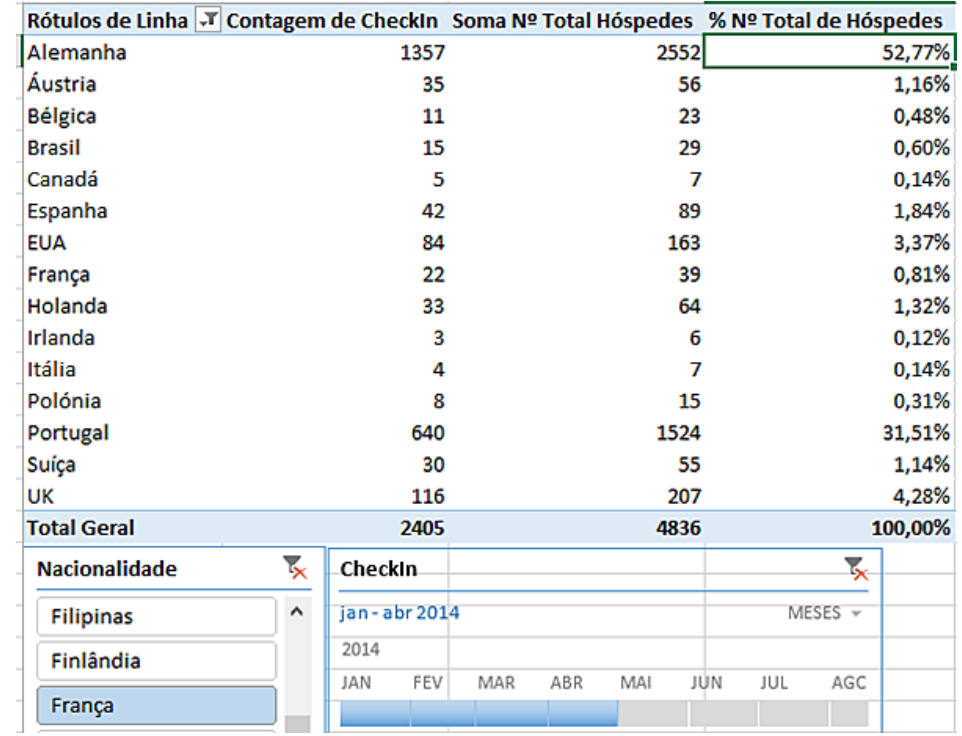

Fonte: Elaboração própria.

Na Figura 3.3 estão patentes os principais operadores turísticos e agências de viagens que serviram como intermediário para a chegada dos hóspedes ao hotel. É relevante salientar que o critério de escolha destas 22 entidades, entre as 522 no total, baseou-se no maior número de check-ins e na maior diversidade de nacionalidades possível.

A Entidade $Q$, agência portuguesa sediada na ilha do Funchal, destaca-se notoriamente das outras entidades, uma vez que serviu de intermediária a 82,13\% do total de hóspedes da Figura 3.3, sendo inclusivamente a única agência que consegue o feito de ter congregado hóspedes das 15 nacionalidades analisadas neste estudo.

Figura 3.3 - Nº de Hóspedes por Agências de Viagens/OT no $1^{\circ}$ Quadrimestre

\begin{tabular}{|c|c|c|c|c|c|c|c|c|c|c|c|c|c|c|c|c|c|}
\hline Rótulos de Linha & 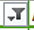 & Alemanha $A$ & Áustria & Bélgica & Brasil & Canadá & Espanha & a EUA & França & Holanda I & da I & tália & Polónia & Portugal & uiça U & K T & tal Geral \\
\hline Entidade $\mathrm{A}$ & & 41 & & & & & & 4 & & 4 & & & & 2 & 5 & & 56 \\
\hline Entidade B & & 1 & & & & & & & & & & & & & & 2 & 3 \\
\hline Entidade C & & 16 & & 2 & 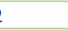 & 1 & 15 & & & 2 & & & & 41 & & 10 & 87 \\
\hline Entidade D & & & & & & 2 & ? & 39 & & 4 & 2 & 2 & & 2 & & 10 & 61 \\
\hline Entidade $\mathrm{E}$ & & 2 & & & & & & 5 & & 3 & & & & 7 & & 4 & 21 \\
\hline Entidade $\mathrm{F}$ & & & & & & & & & & & & & & 15 & & & 15 \\
\hline Entidade $\mathrm{G}$ & & & & & & & 2 & 2 & & & & & & & & 11 & 15 \\
\hline Entidade $\mathrm{H}$ & & & & & & & 3 & 3 & & & & & & 2 & & & 5 \\
\hline Entidade I & & & & & & & & 4 & & & & & & 3 & & 2 & 9 \\
\hline Entidade J & & & & & & & & 2 & 3 & & & & & & & 3 & 8 \\
\hline Entidade $\mathrm{K}$ & & & & & & & & & & 1 & & & & & & 4 & 5 \\
\hline Entidade L & & 14 & 6 & & & & & 2 & 2 & & & & & & & & 24 \\
\hline Entidade $\mathrm{M}$ & & & & & 2 & & & & & & & & & 2 & & 2 & 6 \\
\hline Entidade $\mathrm{N}$ & & & & & & & 2 & 4 & & 1 & & & & 3 & & & 10 \\
\hline Entidade 0 & & 18 & & & & & & & & & & & & & & & 18 \\
\hline Entidade $\mathrm{P}$ & & & & & 2 & & & & 1 & & & & & 4 & & & 7 \\
\hline Entidade Q & & 1999 & 37 & 2 & 11 & 3 & 4 & $4 \quad 56$ & 12 & 30 & 2 & 3 & 13 & 176 & 183 & 33[ & 2399 \\
\hline Entidade $\mathrm{R}$ & & & & & & & 4 & 4 & & & & & & & & & 4 \\
\hline Entidade S & & & & 5 & ; & & & 2 & & & & & & & & & 7 \\
\hline Entidade $\mathrm{T}$ & & 118 & & 2 & ? & & & 4 & & 2 & & & & 4 & 2 & 3 & 135 \\
\hline Entidade U & & & & & & & & & & & & & & 21 & & & 21 \\
\hline Entidade V & & & & & & & 3 & 1 & & & & & & 1 & & & 5 \\
\hline Total Geral & & 2209 & 43 & 11 & 15 & 6 & 33 & 3125 & 18 & 47 & 4 & 5 & 13 & 283 & 258 & 84 & 2921 \\
\hline
\end{tabular}

Fonte: Elaboração própria. 
No $2^{\circ}$ posto, com 4,62\%, está a Entidade T, agência de origem britânica, que, neste caso em concreto, tem sucursal na Alemanha, daí a maioria dos hóspedes que utilizaram esta entidade terem sido alemães. A Entidade T, entre os intermediários que agregaram mais de 2 nacionalidades, foi a entidade que apresentou a maior discrepância entre as nacionalidades, com uma tendência germânica de 87,41\%. A Entidade C queda-se pela $3^{a}$ posição, com 2,98\%, enquanto o $4^{\circ}$ lugar pertence à Entidade $D$, uma empresa norte-americana, que representa 2,09\% do número total de hóspedes da Figura 3.3. Curiosamente, estes 3 intermediários são os únicos, com exceção da Entidade $Q$ a ser representados por 7 nacionalidades.

Em relação às nacionalidades, uma menção honrosa para os EUA, que acumula 4,28\% do número total de hóspedes da Figura 3.3, sendo a $3^{a}$ nação mais destacada, apenas atrás da Alemanha (75,62\%) e de Portugal (9,53\%). Todavia, pode-se afirmar que, ainda que não estejam muitos operadores turísticos/ agências dos EUA representados na figura (4 em 22), esta classificação deve-se à vinda de $76 \%$ de norte-americanos através da Entidade D e Entidade Q. Por outro lado, a Polónia é o único país da figura que recorreu a apenas 1 dos 22 operadores turísticos/agências.

Figura 3.4 - Ocupação por Tipo de Quarto por Noite no $1^{\circ}$ Quadrimestre

\begin{tabular}{|c|c|c|c|c|c|c|c|c|c|c|c|c|c|c|c|}
\hline \multirow[b]{2}{*}{ Rótulos de Linha $\pi$} & \multicolumn{2}{|l|}{ SJ } & \multicolumn{2}{|l|}{ SJVM } & \multicolumn{2}{|l|}{ TW } & \multicolumn{2}{|l|}{ TWF } & \multicolumn{2}{|l|}{ TWFV } & \multicolumn{2}{|l|}{ TWV } & \multicolumn{2}{|c|}{ Total Soma } & \multirow[t]{2}{*}{ Total Média } \\
\hline & Soma & Média & Soma & Média & Soma & Média & Soma & Média & Soma & Média & Soma & Média & & & \\
\hline Alemanha & 9 & $969,08 €$ & 9 & $60,04 €$ & 1019 & $34,16 €$ & 33 & $48,57 €$ & 12 & $266,20 €$ & 275 & $51,44 €$ & & 1357 & $38,70 €$ \\
\hline Áustria & & & & & 20 & $32,35 €$ & 2 & $45,50 €$ & & & 13 & $57,95 €$ & & 35 & $42,61 €$ \\
\hline Bélgica & 2 & $274,30 €$ & & & 3 & $42,00 €$ & & & & & 6 & $62,12 €$ & & 11 & $58,84 €$ \\
\hline Brasil & & $1104,00 €$ & & & 5 & $37,00 €$ & 2 & $74,90 €$ & & $196,00 €$ & 6 & $24,60 €$ & & 15 & $45,49 €$ \\
\hline Canadá & & & & & 3 & $35,00 €$ & & & & & 2 & $44,34 €$ & & 5 & $38,73 €$ \\
\hline Espanha & 2 & $287,04 €$ & & & 5 & $49,56 €$ & 3 & $83,96 €$ & & $592,54 €$ & 27 & $68,50 €$ & & 42 & $71,09 €$ \\
\hline EUA & & & 1 & $30,60 €$ & 31 & $33,65 €$ & 3 & $68,64 €$ & & $372,40 €$ & 46 & $49,48 €$ & & 84 & $44,91 €$ \\
\hline França & 1 & $180,08 €$ & 2 & $88,93 €$ & 9 & $39,76 €$ & 1 & $70,22 €$ & & $179,80 €$ & 8 & $59,95 €$ & & 22 & $56,61 €$ \\
\hline Holanda & & & 2 & $86,52 €$ & 16 & $33,41 €$ & 2 & $78,60 €$ & & & 13 & $49,47 €$ & & 33 & $45,70 €$ \\
\hline Irlanda & & & & & 1 & $40,00 €$ & & & & & 2 & $54,60 €$ & & 3 & $49,73 €$ \\
\hline Itália & & & & & 3 & $31,17 €$ & & & & & 1 & $34,00 €$ & & 4 & $31,88 €$ \\
\hline Polónia & & & & & 6 & $31,26 €$ & 1 & $40,00 €$ & & & 1 & $68,00 €$ & & 8 & $36,95 €$ \\
\hline Portugal & 52 & $298,69 €$ & 20 & $97,97 €$ & 101 & $45,85 €$ & 81 & $81,81 €$ & 62 & $285,16 €$ & 324 & $66,22 €$ & & 640 & $70,44 €$ \\
\hline Suiça & & & 1 & $53,03 €$ & 9 & $34,44 €$ & 1 & $53,00 €$ & & $164,00 €$ & 18 & $54,15 €$ & & 30 & $48,49 €$ \\
\hline UK & 3 & $389,96 €$ & 3 & $65,80 €$ & 35 & $39,17 €$ & 4 & $67,62 €$ & & $355,83 €$ & 68 & $62,36 €$ & & 116 & $56,18 €$ \\
\hline Total Geral & 70 & D $93,29 €$ & 38 & $82,41 €$ & 1266 & $35,30 €$ & 133 & $71,57 €$ & 88 & $881,38 €$ & 810 & $58,81 €$ & & 2405 & $49,34 €$ \\
\hline Checkln & & & & & $r_{x}$ & TipoQua & arto & & $7_{x}$ & Nacional & alidade & & $7 x$ & & \\
\hline jan-abr 2014 & & & & MESES & $s$ - & SGVM & & & $\wedge$ & África o & do Sul & & ^ & & \\
\hline 2014 & & & & & & SJ & & & & Alemar & nha & & & & \\
\hline JAN FEV MAR & $A B R$ & MAI & JUN & JUL & AGC & SJVM & & & & Angola & a & & & & \\
\hline
\end{tabular}

Fonte: Elaboração própria.

Como se pode observar na Figura 3.4, onde está retratado o número de quartos ocupados consoante a sua categoria, o tipo de quarto TW (Twin Vista Terra) foi 
o mais procurado pelo conjunto das 15 nacionalidades, perfazendo um total de $52,64 \%$, contra os 33,68\% do TWV (Twin Vista Mar). À semelhança da Figura 3.2, a Alemanha mantém-se no topo, somando uma percentagem de quartos ocupados pouco acima da metade (56,42\% do total), enquanto Portugal surge em $2^{\circ}$ lugar, embora com $26,61 \%$. Os germânicos são igualmente a nação com maior proporção de TW ocupados relativamente às outras tipologias, com 75,09\%. Por outro lado, a TWV é maioritariamente representada pelos portugueses (40\%), apesar de os alemães também constituírem uma fatia substancial $(33,95 \%)$.

Quanto à média de despesas de alojamento por noite, a Espanha obteve o registo total mais elevado $(71,09 €)$, muito por culpa de a tipologia TWFV (Twin Familiar Vista Mar), a $2^{a}$ mais cara da unidade, representar $11,90 \%$ do número de quartos ocupados por nuestros hermanos. $\mathrm{O} 2^{\circ}$ posto pertence a Portugal, uma vez que foi a nacionalidade com mais ocupação nos tipos de quarto com valor monetário mais elevado: SJ (Suite Júnior Vista Terra) SJVM (Suite Júnior Vista Mar) e TWFV.

Figura 3.5 - Nº de Hóspedes com Consumos na Época Alta

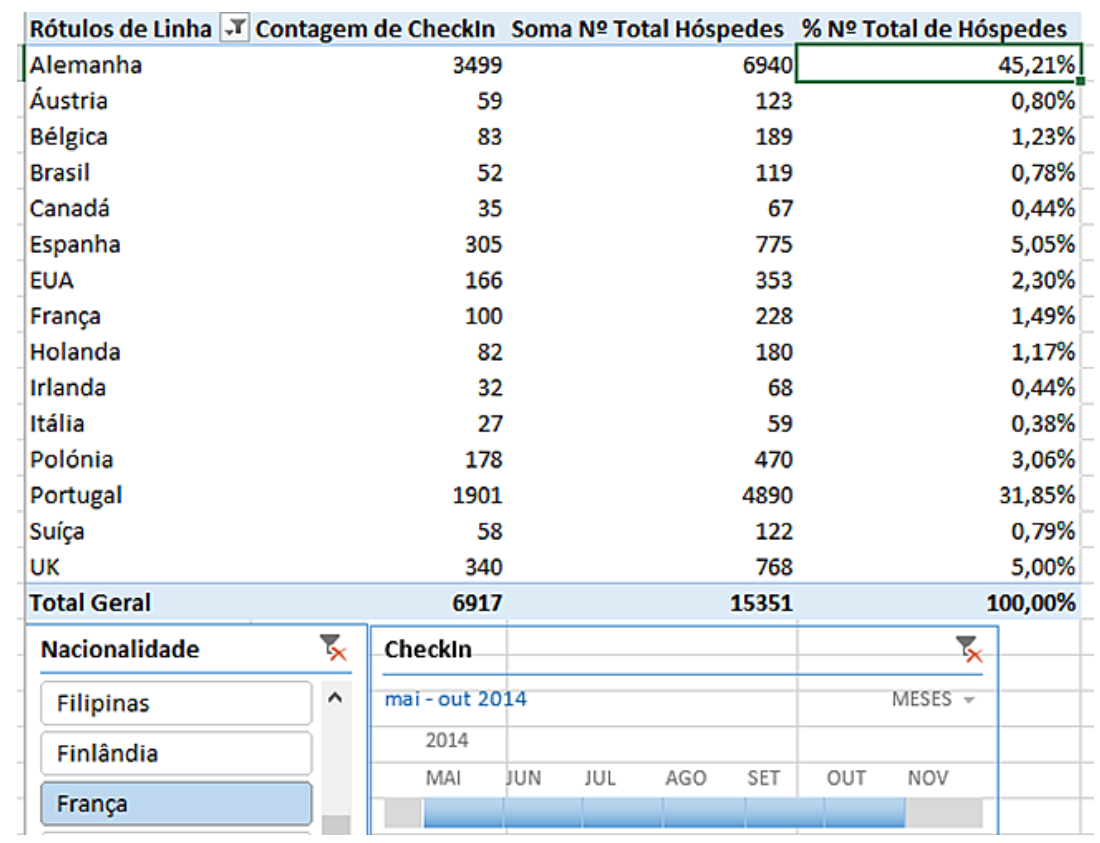

Fonte: Elaboração própria.

Este registo contrasta com a situação da Itália, Polónia e Alemanha, que são 3 das 4 nações com médias de despesas que apresentam valores abaixo dos 40 $€$. Tal facto não é surpreendente, porque estas 3 nacionalidades selecionaram maioritariamente a opção TW, que além de ser a tipologia de alojamento mais barata, inclui igualmente, na média total, os preços de reservas para quarto individual, ou seja, para 1 hóspede. 
Como é bem patente na Figura 3.5, os alemães foram quem mais consumos realizaram durante a época alta (entre maio e outubro), com cerca de 45,21\% do número total de hóspedes, 15351. A Alemanha suplantou Portugal, que ficou por volta dos $31,85 \%$. Ambas as nações representam $77,06 \%$ dos consumos desta estatística.

Na Figura 3.6, são exibidos os dados acerca do consumo de cerveja consoante a nacionalidade dos hóspedes durante a época alta (entre maio e outubro). A Alemanha é o país com maior preferência para este tipo de bebida alcoólica, representando cerca de $72,58 \%$ do total de consumos presentes na Figura 3.6. Tal valor, além de representar um domínio bastante mais considerável do que na Figura 3.5, revela o enorme gosto dos alemães em relação a esta bebida, superiorizando-se aos demais nas quatro modalidades de cerveja.

A caneca é a categoria mais apreciada, muito à custa dos bávaros (78,06\%), enquanto Portugal é, curiosamente, a única nação da figura que opta com mais frequência pela imperial, a modalidade de cerveja mais barata, representando $59,13 \%$ dos consumos de cerveja efetuados por lusitanos, o que ajuda a esclarecer o motivo pela qual é a nacionalidade portadora da média de despesas mais barata $(3,23 €)$. Todas as restantes nacionalidades parecem partilhar a mesma preferência da Alemanha, sendo que a proporção da caneca consumida pelos britânicos em relação à soma total das 4 categorias é elevadíssima (72,82\%), o que explica o facto de serem a nacionalidade detentora da média de gastos por consumo mais elevada (4,02 €). A cerveja de garrafa e a sem álcool revelam pouca adesão.

Figura 3.6 - Consumos de Cerveja na Época Alta

\begin{tabular}{|c|c|c|c|c|c|c|c|c|c|c|c|c|}
\hline \multirow[b]{2}{*}{ Rótulos de Linha $\Psi$} & \multicolumn{3}{|c|}{ Cerveja (garrafa) } & \multicolumn{3}{|c|}{ Cerveja caneca } & Cerveja imperial & \multicolumn{3}{|c|}{ Cerveja sem alcool } & \multirow[t]{2}{*}{ Total Soma } & \multirow[t]{2}{*}{ Total Média } \\
\hline & Soma & & Média & Soma & & Média Soma & & Média Soma & & Média & & \\
\hline Alemanha & & 130 & $2,98 €$ & & 10291 & $4,21 €$ & 4322 & $2,64 €$ & 265 & $2,75 €$ & 15008 & $3,72 €$ \\
\hline Áustria & & 2 & $3,25 €$ & & 139 & $3,61 €$ & 52 & $2,86 €$ & 9 & $3,14 €$ & 202 & $3,43 €$ \\
\hline Bélgica & & 6 & $2,93 €$ & & 77 & $4,39 €$ & 72 & $2,51 €$ & 2 & $2,44 €$ & 157 & $3,40 €$ \\
\hline Brasil & & 4 & $6,10 €$ & & 53 & $3,79 €$ & 52 & $2,77 €$ & & & 109 & $3,39 €$ \\
\hline Canadá & & & & & 31 & $3,67 €$ & 13 & $2,64 €$ & 6 & $2,93 €$ & 50 & $3,34 €$ \\
\hline Espanha & & 14 & $2,93 €$ & & 366 & $4,67 €$ & 193 & $2,66 €$ & 21 & $2,70 €$ & 594 & $3,85 €$ \\
\hline EUA & & 11 & $3,46 €$ & & 211 & $4,00 €$ & 86 & $2,77 €$ & 20 & $2,44 €$ & 328 & $3,57 €$ \\
\hline França & & 6 & $3,66 €$ & & 67 & $3,96 €$ & 62 & $3,00 €$ & & & 135 & $3,55 €$ \\
\hline Holanda & & 5 & $4,88 €$ & & 80 & $4,14 €$ & 57 & $2,88 €$ & & & 142 & $3,68 €$ \\
\hline Irlanda & & 4 & $2,64 €$ & & 43 & $3,73 €$ & 8 & $2,26 €$ & & & 55 & $3,43 €$ \\
\hline Itália & & 4 & $2,44 €$ & & 32 & $4,16 €$ & 9 & $2,61 €$ & & & 45 & $3,67 €$ \\
\hline Polónia & & & & & 71 & $4,52 €$ & 45 & $2,54 €$ & 9 & $2,44 €$ & 125 & $3,59 €$ \\
\hline Portugal & & 114 & $3,24 €$ & & 942 & $3,87 €$ & 1568 & $2,79 €$ & 28 & $2,73 €$ & 2652 & $3,23 €$ \\
\hline Suiça & & & & & 94 & $4,41 €$ & 39 & $2,83 €$ & 2 & $2,44 €$ & 135 & $3,92 €$ \\
\hline UK & & 31 & $3,67 €$ & & 686 & $4,58 €$ & 221 & $2,53 €$ & 4 & $3,25 €$ & 942 & $4,02 €$ \\
\hline Total Geral & & 331 & $3,18 €$ & & 13183] & $4,20 €$ & 6799 & $2,68 €$ & 366 & $2,73 €$ & 20679 & $3,66 €$ \\
\hline Data & & & & $F_{x}$ & Nacio & onalidade & $\bar{x}_{x}$ & Consumo & & $\sqrt{x}$ & & \\
\hline mai- out 2014 & & & & MESES - & & ica do Sul & ^ & Cerveja (garrafa) & & ^ & & \\
\hline 2014 & & & & & & manha & & Cerveja caneca & & & & \\
\hline ABR MAI JUN & JUL & $A G O$ & SET & $\begin{array}{c}\text { NUT } \\
\text { NO } \\
\end{array}$ & Ang & & & Cerveja imperial & & 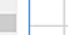 & & \\
\hline
\end{tabular}

Fonte: Elaboração própria. 
Em termos de litros de cerveja consumidos, a diferença entre a Alemanha e a Bélgica, duas nacionalidades conhecidas pelo consumo deste artigo, é abismal: Cerveja de garrafa - 42,9 It da Alemanha contra 1,98 It da Bélgica; Caneca - 4116,4 It da Alemanha contra 30,8 It da Bélgica; Imperial - 864,4 It contra 14,4 lt; Cerveja sem álcool - 66,25 It da Alemanha contra 0,5 It da Bélgica. Estes números denotam novamente um índice de preferência elevado para a cerveja por parte dos germânicos e o domínio na percentagem de consumos nos estabelecimentos de restauração e bebidas do hotel.

No panorama global, pode-se estimar que os hóspedes das 15 nacionalidades consumiram, na sua totalidade, 109,23 litros de cerveja de garrafa, 5273,2 litros de caneca, 1359,8 litros de imperial e apenas 91,5 litros de cerveja sem álcool.

Na Figura 3.7, em que estão presentes algumas das diferentes modalidades de vinho vendidas nos estabelecimentos de restauração e bebidas da unidade, é bastante evidente que a marca Beta é a mais popular entre os hóspedes da unidade $(66,12 \%$ contra os $33,88 \%$ da Alfa), estando o Tinto e o Branco no topo das suas preferências. Apesar de o Beta Tinto ter sido a variedade mais consumida, o Beta Branco é o mais popular da maioria das 15 nacionalidades, embora a margem seja mínima (7 contra 6 do Reserva Tinto).

Figura 3.7 - Consumos de Vinho na Época Alta (venda a copo e garrafa)

\begin{tabular}{|c|c|c|c|c|c|c|c|c|c|c|c|c|c|c|c|c|}
\hline \multirow{3}{*}{$\begin{array}{l}\text { Rótulos de Linha } \\
\text { Alemanha }\end{array}$} & \multicolumn{3}{|c|}{ Vinho Alfa Branco } & \multicolumn{2}{|c|}{ Vinho Alfa Rosé } & \multicolumn{2}{|c|}{ Vinho Alfa Tinto } & \multicolumn{3}{|c|}{ Vinho Beta Branco } & \multicolumn{2}{|c|}{ Vinho Beta Rosé } & \multicolumn{2}{|c|}{ Vinho Beta Tinto } & \multirow[t]{2}{*}{ Total Soma } & \multirow[t]{2}{*}{ Total Média } \\
\hline & Soma & & Média $s$ & Soma & Média & Soma & Média & Soma & & Média & Soma & Média & Soma & Média & & \\
\hline & & 1327 & $75,79 €$ & 787 & $7,50 €$ & 1218 & $6,09 €$ & & 2202 & $3,38 €$ & 1997 & $3,77 €$ & 2490 & $3,72 €$ & 10021 & $4,61 €$ \\
\hline Áustria & & 14 & $4 \quad 6,33 €$ & 4 & $7,72 €$ & 15 & $5,99 €$ & & 40 & $3,22 €$ & 28 & $3,79 €$ & 33 & $3,51 €$ & 134 & $4,26 €$ \\
\hline Bélgica & & 15 & $5 \quad 5,99 €$ & 6 & $7,72 €$ & 9 & $5,87 €$ & & 43 & $3,98 €$ & 19 & $7,95 €$ & 46 & $7,39 €$ & 138 & $6,30 €$ \\
\hline Brasil & & & $5 \quad 6,33 €$ & 3 & $5,69 €$ & 6 & $5,97 €$ & & 17 & $4,47 €$ & 5 & $3,94 €$ & 13 & $5,93 €$ & 49 & $5,21 €$ \\
\hline Canadá & & & $2 \quad 7,72 €$ & & & 6 & $6,71 €$ & & 16 & $2,37 €$ & & & 10 & $6,72 €$ & 34 & $4,80 €$ \\
\hline Espanha & & 31 & $1 \quad 6,14 €$ & 12 & $7,59 €$ & 51 & $5,49 €$ & & 36 & $3,96 €$ & 15 & $4,52 €$ & 51 & $3,99 €$ & 196 & $5,06 €$ \\
\hline EUA & & 23 & $35,77 €$ & 6 & $7,72 €$ & 26 & $6,63 €$ & & 49 & $3,40 €$ & 59 & $4,27 €$ & 54 & $5,63 €$ & 217 & $4,96 €$ \\
\hline França & & & $9 \quad 6,35 €$ & 18 & $7,68 €$ & 17 & $7,72 €$ & & 52 & $3,67 €$ & 43 & $3,54 €$ & 41 & $3,32 €$ & 180 & $4,63 €$ \\
\hline Holanda & & 15 & $5 \quad 5,58 €$ & 16 & $7,42 €$ & 14 & $7,02 €$ & & 42 & $4,02 €$ & 16 & $6,33 €$ & 17 & $3,77 €$ & 120 & $5,36 €$ \\
\hline Irlanda & & & $2 \quad 7,72 €$ & 7 & $5,70 €$ & 1 & $7,72 €$ & & 18 & $4,71 €$ & & $10,57 €$ & 6 & $4,39 €$ & 37 & $5,71 €$ \\
\hline Itália & & & $5 \quad 6,11 €$ & & & 3 & $7,72 €$ & & & & & & 5 & $7,25 €$ & 13 & $6,92 €$ \\
\hline Polónia & & 10 & $0 \quad 5,45 €$ & 7 & $7,72 €$ & 10 & $6,10 €$ & & 11 & $4,17 €$ & 16 & $3,54 €$ & 12 & $4,27 €$ & 66 & $4,94 €$ \\
\hline Portugal & & 219 & $9 \quad 6,30 €$ & 140 & $7,16 €$ & 321 & $6,72 €$ & & 264 & $4,01 €$ & 229 & $4,62 €$ & 334 & $5,08 €$ & 1507 & $5,62 €$ \\
\hline Suíça & & & $9 \quad 5,91 €$ & 7 & $6,85 €$ & 24 & $6,17 €$ & & 14 & $3,19 €$ & 5 & $6,99 €$ & 25 & $7,95 €$ & 84 & $6,43 €$ \\
\hline UK & & 48 & $8 \quad 6,32 €$ & 27 & $7,89 €$ & 48 & $7,17 €$ & & 221 & $4,45 €$ & 160 & $4,14 €$ & 111 & $4,40 €$ & 615 & $4,95 €$ \\
\hline Total Geral & & 1734 & $4 \quad 5,89 €$ & 1040 & $7,45 €$ & 1769 & $6,25 €$ & & 3025 & $3,54 €$ & 2595 & $3,95 €[$ & 3248 & $4,04 €$ & 13411 & $4,80 €$ \\
\hline Data & & & & $7 x$ & Nacion & onalidade & & $\sqrt{x}$ & & & & & & & & \\
\hline mai - out 2014 & & & & MESES - & & ind & & & & & & & & & & \\
\hline mit -2014 & & & & & & ica do Sul & & ^ & & & & & & & & \\
\hline 2014 & & & & Noy & Alem & manha & & & & & & & & & & \\
\hline MAI JUN & JUL & $\mathrm{AGO} S \mathrm{~S}$ & OUT & & Ango & gola & & & & & & & & & & \\
\hline
\end{tabular}

Fonte: Elaboração própria.

Os EUA e a Polónia são as únicas nações a revelar preferência pelo Beta Rosé. Já os hóspedes de nacionalidade espanhola não apresentam uma grande inclinação para nenhuma das duas marcas de vinho da Figura 3.7, sendo mínima a diferença do número de consumos total das 2 . 
À semelhança da Figura 3.5, a tendência germânica (74,72\%) mantém-se igual no que diz respeito ao total dos consumos, enquanto Portugal demonstra uma pobre adesão a esta gama de vinhos, com 11,24\%, muito abaixo em relação aos 31,85\% apresentados na Figura 3.7. A nota de destaque, pela negativa, vai para a Espanha, que, com apenas 1,46\% dos consumos (5,05\% na Figura 3.5), é ultrapassada pelos EUA (1,62\%).

Antes de analisar a média de preços sem IVA incluído, torna-se necessário referir que a marca Beta é 0,80 € mais cara do que a Alfa na venda a copo e 3,50 $€$ na venda a garrafa.

A média por consumo mais inferior pertence à Áustria $(4,26 €)$, muito embora tenha uma das percentagens mais elevadas em termos de proporção do consumo da marca Beta em relação à soma total (75,47\%), enquanto a Itália detém a média mais elevada $(6,92 €)$. A Bélgica é a $3^{a}$ média mais cara, visto que a Beta perfaz $78,26 \%$ do total de consumos realizados por belgas, um dos maiores registos de consumo desta marca entre as 15 nacionalidades.

Como se pode observar nas figuras 3.8 e 3.9, o artigo Refrigerante foi o mais consumido no Bar $\mathrm{Y}$ e o artigo Café no Bar X, embora a diferença de quantidade entre os dois pontos de venda seja bastante considerável. Entre maio e outubro, o Bar $Y$ obteve cerca de mais $11 \%$ de consumos do que o Bar $X$ em relação ao valor total das 2 figuras.

O Café foi o artigo mais requisitado no Bar Z e o $2^{\circ}$ mais pedido no Bar $Y$ por parte dos lusitanos, o que, tudo somado, representa 47,33\% do total de consumos dos portugueses. Embora o Refrigerante tenha sido o artigo mais consumido pelos brasileiros no Bar $Y(41,86 \%$ do total de consumos pelo Brasil), estes revelam igualmente uma enorme propensão para o consumo de Café (39,53\%). Tendo em consideração que o Café é o artigo com o preço mais acessível de ambas as figuras $(1,80 €)$, tal facto poderá ajudar a explicar as médias de gastos por consumo mais baixas do Bar X (Brasil) e Bar Y (Portugal).

Quanto ao Cocktail do Dia, a quantidade de consumos no Bar Y é pouco mais de metade $(51,61 \%)$ em relação ao mesmo artigo no Bar $X$, sendo surpreendentemente o UK a nacionalidade que mais cocktails consumiu, a seguir à Alemanha, no conjunto dos 2 bares. Por outro lado, é no Bar Y que o Vinho do Porto e a Pina Colada são notoriamente bastante mais requisitados 
do que no Bar X, representando respetivamente cerca de 88,31\% e 95,58 \% da soma total do artigo correspondente em ambos os pontos de venda.

Figura 3.8 - Consumos de Bebidas e Cafetaria na Época Alta (Bar X)

\begin{tabular}{|c|c|c|c|c|c|c|c|c|c|c|c|c|c|c|c|c|c|c|c|c|c|c|c|c|}
\hline \multirow[b]{2}{*}{ Rótulos $\sqrt{\mathrm{N}}$} & \multicolumn{2}{|c|}{ Batidos } & \multirow{2}{*}{$\begin{array}{l}\text { Cafés } \\
\text { Soma I }\end{array}$} & \multirow[b]{2}{*}{ Média } & \multicolumn{2}{|l|}{ Caipirinha } & \multicolumn{2}{|l|}{ Cappuccinos } & \multirow{2}{*}{\multicolumn{2}{|c|}{$\begin{array}{l}\text { Chás } \\
\text { Soma Média }\end{array}$}} & \multicolumn{2}{|c|}{ Cocktail dia } & \multicolumn{2}{|l|}{ Mojito } & \multicolumn{2}{|c|}{ Pina Colada } & \multirow{2}{*}{\multicolumn{2}{|c|}{$\begin{array}{l}\text { Porto } \\
\text { Soma Média }\end{array}$}} & \multicolumn{2}{|c|}{ Refrigerantes } & \multicolumn{2}{|l|}{ Sangria } & \multicolumn{2}{|c|}{ Total Soma Total n } \\
\hline & Soma & Média S & & & Soma & Média & Soma & Média & & & Soma & Média & Soma $n$ & Média & Soma & Média & & & Soma & Média & Soma & Média & & \\
\hline Alemanha & 5 & $3,66 €$ & 339 & $2,09 €$ & 22 & $7,71 €$ & 1066 & $2,78 €$ & 39 & $1,93 €$ & 45 & $6,86 €$ & 10 & $7,55 €$ & 9 & $6,79 €$ & 146 & $6,62 €$ & 503 & $3,39 €$ & 30 & $9,16 €$ & & $323,13 €$ \\
\hline Áustria & & & 1 & $1,46 €$ & & & 15 & $2,98 €$ & 1 & $1,79 €$ & 2 & $9,76 €$ & & & & & & & 23 & $2,96 €$ & 1 & $8,94 €$ & & $33,27 €$ \\
\hline Bélgica & 8 & $7,32 €$ & 4 & $2,28 €$ & & & 21 & $2,19 €$ & & & 9 & $6,27 €$ & & & & & & & 90 & $3,97 €$ & 1 & $8,94 €$ & & $333,96 €$ \\
\hline Brasil & & & 34 & $1,71 €$ & 1 & $5,28 €$ & 6 & $2,08 €$ & & & 3 & $4,88 €$ & 6 & $5,19 €$ & & & & & 36 & $3,26 €$ & & & & $362,80 €$ \\
\hline Canadá & & & 4 & $2,93 €$ & 1 & $5,28 €$ & & & & & & & 1 & $5,28 €$ & & & & & 15 & $3,44 €$ & & $12,20 €$ & & $234,62 €$ \\
\hline Espanha & 2 & $3,48 €$ & 88 & $2,21 €$ & 4 & $5,15 €$ & 31 & $2,30 €$ & & & 10 & $7,89 €$ & 13 & $8,59 €$ & 4 & $6,70 €$ & & & 92 & $3,47 €$ & 3 & $8,64 €$ & & $473,47 €$ \\
\hline EUA & 3 & $5,13 €$ & 8 & $1,85 €$ & 3 & $5,28 €$ & 33 & $2,36 €$ & 1 & $1,79 €$ & 5 & $5,86 €$ & 3 & $7,40 €$ & & & & & 110 & $3,31 €$ & 4 & $8,94 €$ & & $703,44 €$ \\
\hline França & 2 & $7,32 €$ & 10 & $2,50 €$ & 1 & $5,28 €$ & 37 & $3,15 €$ & & & & & 1 & $5,28 €$ & & & & & 56 & $4,00 €$ & 1 & $8,94 €$ & & $83,76 €$ \\
\hline Holanda & 3 & $3,66 €$ & 10 & $1,72 €$ & & & 25 & $2,63 €$ & 2 & $1,79 €$ & 4 & $4,88 €$ & 2 & $10,57 €$ & & & & & 60 & $3,97 €$ & 2 & $8,94 €$ & & $883,57 €$ \\
\hline Irlanda & & & & & & & 14 & $3,58 €$ & & & & & & & & & & & 5 & $4,39 €$ & & & & $193,82 €$ \\
\hline Itália & & & 4 & $1,85 €$ & & & 3 & $2,69 €$ & & & & & & & & & & & 33 & $3,86 €$ & & & & $03,54 €$ \\
\hline Polónia & 2 & $3,66 €$ & 14 & $1,87 €$ & 4 & $10,57 €$ & 12 & $2,15 €$ & 1 & $1,79 €$ & 2 & $4,88 €$ & 6 & $7,93 €$ & 31 & $15,85 €$ & & & 12 & $3,07 €$ & 2 & $8,94 €$ & & $583,92 €$ \\
\hline Portugal & 38 & $4,17 €$ & 952 & $2,13 €$ & 26 & $5,29 €$ & 83 & $2,67 €$ & 11 & $1,66 €$ & 19 & $5,79 €$ & 12 & $7,04 €$ & 4 & $6,34 €$ & 66 & $6,10 €$ & 991 & $3,24 €$ & 58 & $8,65 €$ & & $003,08 €$ \\
\hline Suíça & & & 6 & $2,28 €$ & & & 5 & $2,98 €$ & & & & & 11 & $29,07 €$ & & & & & 18 & $4,04 €$ & & & & $106,03 €$ \\
\hline UK & 13 & $5,29 €$ & 26 & $2,02 €$ & & & 87 & $2,71 €$ & 13 & $1,92 €$ & 25 & $9,31 €$ & 4 & $5,28 €$ & 9 & $7,66 €$ & 63 & $3,30 €$ & 439 & $3,92 €$ & 15 & $11,44 €$ & & $374,11 €$ \\
\hline Total Geral & 76 & $4,53 €$ & 1500 & $2,11 €$ & 62 & $6,21 €$ & 1438 & $2,74 €$ & 68 & $1,87 €$ & 124 & $6,85 €$ & 69 & $8,07 €$ & 29 & $7,42 €$ & 265 & $5,41 €$ & 2483 & $3,46 €$ & 119 & $9,20 €$ & & $343,30 €$ \\
\hline Data & & & & & & $7_{x}$ & Naciona & alidade & & $F_{x}$ & Ponto & oVenda & & $z_{x}$ & Consum & & & $r_{x}$ & & & & & & \\
\hline mai - out 201 & & & & & MESE & $\overline{E S}=$ & África & do Sul & & $\hat{\imath}$ & Bar & piscina L & LAG & & Margar & arita & & $\wedge$ & & & & & & \\
\hline 2014 & & & & & & & Alema & anha & & & & hion bar & r LAG & & Mojito & & & & & & & & & \\
\hline ABR $\quad$ MAI & JUI & JUL & AGC & SO $\quad$ SET & OUT & NO' & Angol & & & & Inev & vitavel L & & & Nectar & rde frut & & 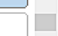 & & & & & & \\
\hline
\end{tabular}

Fonte: Elaboração própria.

Não deixa igualmente de ser curioso que o Mojito, no Bar X, tenha obtido um número de pedidos equilibrado entre 4 países (Alemanha, Espanha, Portugal e Suíça) mas, no Bar Y, a percentagem é bastante desnivelada para o lado dos germânicos (47,92\% do total).

Por último, é de ressalvar que a média mais alta pertence naturalmente à Sangria $(9,14 €)$, ao passo que a Polónia, tendo em conta ambas as figuras, é a detentora da média por consumo mais cara $(5,17 €)$, apesar de ter consumido o artigo Café em maior número.

Em conclusão, o Bar X obteve mais pedidos por parte dos portugueses (36,70\% dos consumos contra os 34,73\% dos alemães), enquanto no Bar $Y$ se verificou uma maior tendência germânica (49,61\% contra os $26,22 \%$ dos lusitanos). O UK é a $2^{a}$ nação com mais consumos em 3 dos artigos da figura (Cappuccino, Cocktail do Dia e Porto), enquanto a Bélgica, que, além de ser a $3^{a}$ nacionalidade com mais pedidos de Refrigerantes e de Caipirinha, destaca-se na $5^{a}$ posição na classificação total dos consumos do Bar Y (Figura 3.9), com 2,60\%.

A Figura 3.10 revela uma maior predominância germânica (59,71\% do total) do que na época alta (Figura 3.5), uma vez que setembro e outubro são dois dos meses mais frequentados por alemães (92,16\% dos 3278 da figura 3.10 consumiram num destes meses), o que deixa Portugal muito abaixo em relação ao $1^{\circ}$ quadrimestre (Figura 3.2) e época alta (Figura 3.5), com apenas 19,84\%. 
Figura 3.9 - Consumos de Bebidas e Cafetaria na Época Alta (Bar Y)

\begin{tabular}{|c|c|c|c|c|c|c|c|c|c|c|c|c|c|c|c|c|c|c|c|c|c|c|c|c|c|c|}
\hline \multirow{2}{*}{\multicolumn{2}{|c|}{$\begin{array}{ll} & \text { Batidos } \\
\text { Rótulos } \sqrt{\top} \text { Soma }\end{array}$}} & & \multirow{2}{*}{$\begin{array}{l}\text { Cafés } \\
\text { Soma n }\end{array}$} & \multicolumn{3}{|c|}{ Caipirinha } & \multicolumn{3}{|c|}{ Cappuccinos } & \multirow{2}{*}{\multicolumn{2}{|c|}{$\begin{array}{l}\text { Chás } \\
\text { Soma Média }\end{array}$}} & \multicolumn{2}{|c|}{ Cocktail dia } & \multirow{2}{*}{\multicolumn{2}{|c|}{$\begin{array}{l}\text { Mojito } \\
\text { Soma Média }\end{array}$}} & \multicolumn{2}{|c|}{ Pina Colada } & \multirow{2}{*}{\multicolumn{2}{|c|}{$\begin{array}{l}\text { Porto } \\
\text { Soma Média }\end{array}$}} & \multicolumn{2}{|c|}{ Refrigerantes } & \multicolumn{2}{|c|}{ Sangria } & \multicolumn{2}{|c|}{ Total Soma Total Média } \\
\hline & & & lédia S & & Média s & Soma & Média & Soma & & Média $S$ & & & Soma & Média $s$ & & & Soma & Média $s$ & & & Soma & Média & Soma & Média & & \\
\hline Alemanha & & & $66 €$ & 4612 & $2,23 €$ & 219 & $96,42 €$ & & 537 & $2,64 €$ & 312 & $2,40 €$ & 41 & $11,11 €$ & 161 & $6,45 €$ & 135 & $6,52 €$ & 397 & $4,79 €$ & 318 & $3,10 €$ & 73 & $8,99 €$ & 2382 & $4,24 €$ \\
\hline Áustria & & &, $66 €$ & 41 & $1,63 €$ & & & & 3 & $2,69 €$ & & & & & 3 & $7,93 €$ & 8 & $5,28 €$ & 20 & $3,59 €$ & 5 & $54,31 €$ & 1 & $8,94 €$ & 45 & $4,12 €$ \\
\hline Bélgica & & & & 312 & $2,21 €$ & & $612,49 €$ & & 19 & $2,43 €$ & 62 & $2,69 €$ & 6 & $9,76 €$ & 8 & $5,96 €$ & 4 & $7,04 €$ & 16 & $4,22 €$ & 35 & $53,06 €$ & 1 & $8,94 €$ & 152 & $4,43 €$ \\
\hline Brasil & & & & 62 & $2,12 €$ & & & & 5 & $1,79 €$ & & & & & 4 & $5,28 €$ & 2 & $5,28 €$ & 1 & $7,32 €$ & 5 & $52,49 €$ & & & 23 & $3,28 €$ \\
\hline Canadá & & & & & & & & & 4 & $3,58 €$ & & & & & 5 & $6,60 €$ & & & 3 & $3,05 €$ & & $12,44 €$ & & & 13 & $4,52 €$ \\
\hline Espanha & & &, $61 €$ & 332 & $2,28 €$ & 15 & $5 \quad 6,52 €$ & & 39 & $2,38 €$ & 172 & $2,62 €$ & & & 29 & $7,92 €$ & 6 & $5,19 €$ & 3 & $4,58 €$ & 20 & $2,88 €$ & 1 & $8,94 €$ & 170 & $3,98 €$ \\
\hline EUA & & & , 32€ & 122 & $2,36 €$ & & & & 12 & $2,64 €$ & 31 & $1,79 €$ & 4 & $9,76 €$ & 6 & $7,93 €$ & 6 & $5,28 €$ & 6 & $6,41 €$ & 32 & $23,10 €$ & 7 & $8,94 €$ & 90 & $4,41 €$ \\
\hline França & & & & 241 & $1,92 €$ & & $5 \quad 5,28 €$ & & 6 & $2,69 €$ & 91 & $1,99 €$ & & & 9 & $7,93 €$ & 5 & $8,81 €$ & 10 & $4,62 €$ & 21 & $13,26 €$ & 1 & $8,94 €$ & 90 & $3,72 €$ \\
\hline Holanda & & & & 112 & $2,57 €$ & & $114,53 €$ & & 6 & $1,79 €$ & $\begin{array}{ll}4 & 1\end{array}$ & $1,79 €$ & 1 & $4,88 €$ & 5 & $6,47 €$ & & & 2 & $6,10 €$ & 21 & $13,42 €$ & 2 & $8,94 €$ & 63 & $4,55 €$ \\
\hline Irlanda & & & & 41 & $1,58 €$ & & & & 3 & $1,79 €$ & 11 & $1,79 €$ & & & & & & & 1 & $3,05 €$ & 16 & $54,79 €$ & & & 25 & $3,23 €$ \\
\hline Itália & & & & 21 & $1,46 €$ & & $15,28 €$ & & & & 21 & $1,79 €$ & & & 2 & $5,28 €$ & & & & & 2 & $2,56 €$ & & & 9 & $3,05 €$ \\
\hline Polónia & & & & 132 & $2,72 €$ & & & & 2 & $3,58 €$ & 52 & $2,24 €$ & & & 10 & $8,81 €$ & 2 & $5,28 €$ & & & 6 & $53,66 €$ & & $10,03 €$ & 41 & $5,17 €$ \\
\hline Portugal & & 144,1 & $1,18 €$ & 6852 & $2,09 €$ & 78 & $8 \quad 5,98 €$ & & 70 & $2,13 €$ & 1172 & $2,12 €$ & 8 & $5,23 €$ & 48 & $5,44 €$ & 29 & $5,19 €$ & 39 & $4,01 €$ & 164 & $42,74 €$ & 7 & $9,52 €$ & 1259 & $2,89 €$ \\
\hline Suiça & & & & 161 & $1,93 €$ & & $8 \quad 6,04 €$ & & 13 & $2,57 €$ & & & 1 & $4,39 €$ & 6 & $7,93 €$ & 7 & $7,19 €$ & 12 & $5,03 €$ & 22 & $23,23 €$ & & & 85 & $4,02 €$ \\
\hline UK & & 144,6 & $1,66 €$ & 221 & $1,84 €$ & 10 & $0 \quad 6,47 €$ & & 71 & $2,70 €$ & $\begin{array}{ll}10 & 1\end{array}$ & $1,99 €$ & 3 & $4,88 €$ & 40 & $7,29 €$ & 15 & $5,55 €$ & 52 & $4,98 €$ & 111 & $13,16 €$ & 6 & $9,48 €$ & 354 & $4,07 €$ \\
\hline Total Geral & & 474,1 & $1,16 €[$ & 13242 & $2,14 €$ & 373 & $3 \quad 6,63 €$ & & 790 & $2,56 €$ & 2052 & $2,18 €$ & 64 & $8,84 €$ & 336 & $6,58 €$ & 219 & $6,15 €$ & 562 & $4,69 €$ & 779 & $3,06 €$ & 102 & $9,08 €$ & 4801 & $3,86 €$ \\
\hline Data & & & & & & & $I_{x}$ & & Nacione & aliadade & & $F_{x}$ & PontoV & Venda & & $7 x$ & Consum & & & $\sqrt{x}$ & & & & & & \\
\hline mai-out 20 & & & & & & ME & MESES - & & África & do Sul & & ^ & Bar pi & iscina LAC & & & Fernet & t branca & & $\wedge$ & & & & & & \\
\hline 2014 & & & & & & & & & Alema & lanha & & & Fashic & ion bar LA & LAG & & Gelado & & & & & & & & & \\
\hline $\begin{array}{ll}A B R & M A \\
& \end{array}$ & A. JUN & JN & JUL & AGO & D SET & T OUT & \begin{tabular}{|c|} 
\\
\end{tabular} & & Arábia & a Saudita & & & Inevit & tavel LAG & & & Gin & & & $\square$ & & & & & & \\
\hline
\end{tabular}

Fonte: Elaboração própria.

Como é possível constatar na Figura 3.11, apenas surgem 12 das 15 nacionalidades analisadas devido à ausência de consumos por parte de austríacos, italianos e polacos. O prato principal mais solicitado entre setembro e dezembro foi o Bacalhau Assado, embora não seja uma tendência maioritária $(14,65 \%)$, enquanto os menos procurados foram, curiosamente, dois pratos vegetarianos: a Lasanha Vegetariana (2,53\%) e o Risotto de Espargos (2,78\%).

Figura 3.10 - No de Hóspedes com Consumos no $3^{\circ}$ Quadrimestre

\begin{tabular}{|c|c|c|c|c|c|c|c|}
\hline Rótulos de Linha & Contagen & de Checkln S & Soma № T & al Hós & edes & \% № Total de Hó & óspedes \\
\hline Alemanha & & 1686 & & & 3278 & & $59,71 \%$ \\
\hline Áustria & & 8 & & & 17 & & $0,31 \%$ \\
\hline Bélgica & & 22 & & & 46 & & $0,84 \%$ \\
\hline Brasil & & 8 & & & 20 & & $0,36 \%$ \\
\hline Canadá & & 25 & & & 44 & & $0,80 \%$ \\
\hline Espanha & & 88 & & & 214 & & $3,90 \%$ \\
\hline EUA & & 45 & & & 87 & & $1,58 \%$ \\
\hline França & & 45 & & & 96 & & $1,75 \%$ \\
\hline Holanda & & 28 & & & 54 & & $0,98 \%$ \\
\hline Irlanda & & 28 & & & 56 & & $1,02 \%$ \\
\hline Itália & & 6 & & & 12 & & $0,22 \%$ \\
\hline Polónia & & 30 & & & 69 & & $1,26 \%$ \\
\hline Portugal & & 489 & & & 1089 & & $19,84 \%$ \\
\hline Suiça & & 24 & & & 47 & & $0,86 \%$ \\
\hline UK & & 171 & & & 361 & & $6,58 \%$ \\
\hline Total Geral & & 2703 & & & 5490 & & $100,00 \%$ \\
\hline Nacionalidade & $\nabla_{x}$ & Checkln & & & & $r_{x}$ & \\
\hline Filipinas & $\wedge$ & set - dez 2014 & & & & MESES - & \\
\hline Finlândia & & 2014 & & & & & \\
\hline & & JUN & AGO & SET & OUT & NOV DEZ & \\
\hline França & & & & & & & \\
\hline
\end{tabular}

Fonte: Elaboração própria.

O Bife do Lombo, embora tendo obtido um menor índice de consumo do que o Bacalhau Assado, com 12,63\%, foi a iguaria com maior número de preferências das 12 nacionalidades (4 contra 3 do Bacalhau Assado), não obstante o facto de ser a opção mais cara (22 €) dos 13 pratos exibidos na Figura 3.11. 
Ao contrário do que ocorre na Figura 3.10, Portugal efetuou um maior número de consumos (22,98\%), suplantando os $20,71 \%$ da Alemanha e os $15,15 \%$ do UK. Por outro lado, ainda em comparação com a Figura 3.10, a Espanha, apesar de apresentar um registo maior nos consumos (5,30\%), desce 3 posições, sendo superada pelos EUA (9,09\%), a França (8,33\%) e, inclusivamente, a Suíça (7,07\%), o que denota uma predileção evidente dos suiços pela frequência do Restaurante X.

O setor de Vegetariano é o menos favorito dos portugueses (9,89\%), o que também se reflete no panorama geral, uma vez que os 4 pratos pertencentes a este setor representam somente $16,41 \%$ do valor total. Já o setor da Carne integra 44,44\% dos consumos, ultrapassando o índice de preferência do Peixe (39,14\%), o que não deixa de ser natural, porque estão representados 5 pratos de Carne e 4 de Peixe na Figura 3.11.

A média de despesas por consumo mais elevada pertence à Suíça (19,48 $€)$, uma vez que o Bife do Lombo, a iguaria mais cara, constitui 39,29\% do seu valor total de consumos. Em sentido inverso, com a média mais inferior, está Portugal, que se faz valer do facto de 2 dos pratos mais baratos, o Filete de Peixe Galo e o Peito de Frango (12 €), terem adquirido conjuntamente uma percentagem de consumos lusitanos num valor aproximado de $31,87 \%$.

Figura 3.11 - Consumos dos Pratos Principais do Restaurante X no $3^{\circ}$ Quadrimestre

\begin{tabular}{|c|c|c|c|c|c|c|c|c|c|c|c|c|c|c|c|c|c|c|c|c|}
\hline Rótulos de Linha & \multicolumn{2}{|c|}{ Alemanha } & \multicolumn{2}{|c|}{ Bélgica } & Brasil & Canadá & \multicolumn{2}{|c|}{ Espanha } & EUA & \multicolumn{2}{|l|}{ França } & Holanda & $\begin{array}{l}\text { Irlanda } \\
\text { Soma Média }\end{array}$ & \multicolumn{2}{|c|}{$\begin{array}{l}\text { Portugal } \\
\text { Somádi }\end{array}$} & \multicolumn{2}{|l|}{ Suiça } & $\begin{array}{l}\text { UK } \\
\text { Soma Média }\end{array}$ & \multicolumn{2}{|c|}{$\begin{array}{l}\text { Total Total } \\
\text { Soma Média }\end{array}$} \\
\hline Bacalhau Assado & 9 & $11,93 €$ & & $12,20 €$ & $112,20 €$ & $112,20 €$ & & $21,95 €$ & $530,49 €$ & & $21,95 €$ & $212,20 €$ & $212,20 €$ & $€ \quad 16$ & $11,71 €$ & & $12,20 €$ & $\varepsilon \quad 212,20 €$ & 58 & $314,90 €$ \\
\hline Bife da Vazia & 3 & $11,79 €$ & & $10,98 €$ & $112,20 €$ & $112,20 €$ & & $12,20 €$ & $212,20 €$ & & $12,20 €$ & $112,20 €$ & $112,20 €$ & 13 & $11,07 €$ & 2 & $212,20 €$ & $€ \quad 1512,90 €$ & 43 & $312,03 €$ \\
\hline Bife do lombo & 9 & $19,90 €$ & & $17,00 €$ & $117,89 €$ & & & $17,89 €$ & $117,89 €$ & & & $717,89 €$ & $326,83 €$ & 6 & $17,29 €$ & 11 & $139,35 €$ & $617,89 €$ & 50 & $21,13 €$ \\
\hline Bife pojadouro & 4 & $9,76 €$ & & & $19,76 €$ & $19,76 €$ & & & $19,76 €$ & & & & & & $11,22 €$ & 1 & $19,76 €$ & $49,76 €$ & 17 & $710,13 €$ \\
\hline Filete Peixe Galo & 10 & $11,95 €$ & 1 & $9,76 €$ & $19,76 €$ & & & $13,01 €$ & $19,76 €$ & 29 & $9,76 €$ & & & 16 & $10,81 €$ & & & $811,01 €$ & 43 & $311,14 €$ \\
\hline Lasanha vegetariana & 3 & $9,76 €$ & & & & & & & $4 \quad 9,76 €$ & 19 & $9,76 €$ & & & 1 & $9,76 €$ & 1 & $19,76 €$ & & 10 & $9,76 €$ \\
\hline Linguine Nero & & $17,08 €$ & & & & & & $12,20 €$ & $212,20 €$ & & $12,20 €$ & $210,98 €$ & $112,20 €$ & & $10,98 €$ & & $224,39 €$ & $312,20 €$ & 21 & $114,03 €$ \\
\hline Lombinho de Porco & 4 & $9,27 €$ & & & $19,76 €$ & $219,51 €$ & & & $314,64 €$ & & $14,64 €$ & & & 5 & $9,61 €$ & & & $711,39 €$ & 25 & $11,49 €$ \\
\hline Polvo Assado à Lagareiro & 4 & $19,51 €$ & & & $314,63 €$ & & & & $617,56 €$ & & $14,63 €$ & & & & $10,73 €$ & & $229,27 €$ & $518,29 €$ & & $416,97 €$ \\
\hline Ravioli & 10 & $9,76 €$ & & & & $19,76 €$ & & & $29,76 €$ & 29 & $9,76 €$ & & & & $10,93 €$ & & & $29,76 €$ & 23 & $310,03 €$ \\
\hline Risotto de espargos & & & & & & & 1 & $9,76 €$ & $19,76 €$ & 39 & $9,76 €$ & $19,76 €$ & & & $9,76 €$ & 1 & $19,76 €$ & $39,76 €$ & 11 & $19,76 €$ \\
\hline Salmão Braseado & 6 & $12,20 €$ & & & & $112,20 €$ & & & $520,33 €$ & & $11,90 €$ & $110,98 €$ & & & $10,49 €$ & 6 & $518,30 €$ & $212,20 €$ & 30 & $13,65 €$ \\
\hline Total Geral & 82 & $12,39 €$ & 5 & $13,39 €$ & $912,83 €$ & $812,20 €$ & 21 & $16,52 €$ & $3614,58 €$ & 3313 & $13,11 €$ & $1514,29 €$ & $816,03 €$ & 91 & $11,24 €$ & 28 & в $22,18 €$ & $6012,64 €$ & 396 & $513,26 €$ \\
\hline Data & & & & $I_{x}$ & Consumo & & $z_{x}$ & Naciona & nalidade & $\sqrt{x}$ & Ponto & toVenda & $\bar{l}_{x}$ & & & & & & & \\
\hline set-dez 2014 & & & & MESES - & Água C/ & / Gás & ^ & África & a do Sul & ^ & & evitavel LAG & & & & & & & & \\
\hline 2014 & & & & & Água S/ & Gás & & Alema & nanha & & & ersatil LAG & & & & & & & & \\
\hline JUN JUL & SET & OUT & NOV & DEZ & Aguarde & ente & & Angol & & & & r niscinalAG & & & & & & & & \\
\hline
\end{tabular}

Fonte: Elaboração própria.

Na Figura 3.12, emq ue está representado o número de consumos efetuados através dos regimes de alojamento da unidade consoante a nacionalidade, é novamente patente a enorme superioridade dos portugueses e dos alemães em 
relação aos demais, sendo a soma das percentagens de ambas as nacionalidades de $83,72 \%$. Tanto Portugal (44,95\%) como Alemanha (38,77\%) revelam grande propensão para consumos por meio do regime de MP (Meia Pensão) Adulto. Aliás, a percentagem de consumo dos lusitanos através do suplemento de MP Adulto e Criança é bem evidente: $87,19 \%$ do total das 8 modalidades.

Todavia, pode-se afirmar que a preferência pelos regimes de alojamento entre as 14 nacionalidades (a Itália não surge na figura, pelo que se assume que terá usufruído apenas do regime de APA, isto é, Alojamento e Pequeno-Almoço) é bastante dividida, sendo que 8 optaram com mais frequência pelo MP Adulto e 6 pelo AI (All Inclusive) Bebidas e Comidas Adulto, embora este primeiro tenha representado $59,45 \%$ do total de consumos da Figura 3.12. O regime de MP inclui apenas pequeno-almoço e jantar, ao passo que o AI inclui todas as refeições do dia e algumas das bebidas servidas no Bar X e $Y$ ou no Restaurante $X$. Desta forma, tendo em consideração que o MP custa menos $30 €$ do que o $\mathrm{AI}$, poderá ter sido esse o fator decisivo de seleção entre um e outro.

Figura 3.12 - Regimes de Alojamento no $3^{\circ}$ Quadrimestre do Ano

\begin{tabular}{|c|c|c|c|c|c|c|c|c|c|c|c|c|c|c|c|c|c|c|c|c|}
\hline \multirow{2}{*}{ Rótulos de Linha } & \multicolumn{3}{|c|}{ Al BEBIDAS ADULTO } & \multicolumn{5}{|c|}{ AI BEBIDAS CRIANÇA AI COMIDAS ADULTO } & \multicolumn{2}{|c|}{ AI COMIDAS CRIANÇA } & \multicolumn{2}{|c|}{ MP ADULTO } & \multicolumn{2}{|c|}{ MP CRIANÇA } & \multicolumn{2}{|c|}{ PC ADULTO } & \multicolumn{2}{|c|}{ PC CRIANÇA } & \multirow[t]{2}{*}{ Total Soma } & \multirow[t]{2}{*}{ Total Máximo } \\
\hline & I Soma & & Máximo & Soma & & Máximo $\mathrm{s}$ & & Máximo & Soma & iximo & Soma & Máximo & Soma & Máximo & Soma & Máximo & Soma & Máximo & & \\
\hline Alemanha & & 3252 & $19,02 €$ & & 142 & $6,34 €$ & 3262 & $110,57 €$ & 142 & $14,80 €$ & 5053 & $243,25 €$ & 104 & $6,50 €$ & 26 & $26,02 €$ & & & 11981 & $243,25 €$ \\
\hline Áustria & & 80 & $12,68 €$ & & & & 80 & $29,59 €$ & & & 14 & $13,01 €$ & & & & & & & 174 & $29,59 €$ \\
\hline Bélgica & & 142 & $12,68 €$ & & & & 142 & $29,59 €$ & & & 206 & $13,01 €$ & & & & & & & 490 & $29,59 €$ \\
\hline Canadá & & & & & & & & & & & 44 & $13,01 €$ & & & & & & & 44 & $13,01 €$ \\
\hline Espanha & & 164 & $19,02 €$ & & 8 & $6,34 €$ & 164 & $44,39 €$ & 8 & $14,80 €$ & 345 & $19,51 €$ & 38 & $6,50 €$ & 31 & $39,02 €$ & & & 758 & $44,39 €$ \\
\hline EUA & & 18 & $12,68 €$ & & & & 18 & $29,59 €$ & & & & & & & & & & & 36 & $29,59 €$ \\
\hline França & & 36 & $12,68 €$ & & & & 36 & $29,59 €$ & & & 60 & $13,01 €$ & 7 & $3,25 €$ & & & & & 139 & $29,59 €$ \\
\hline Holanda & & 46 & $12,68 €$ & & & & 46 & $29,59 €$ & & & 14 & $13,01 €$ & & & & & & & 106 & $29,59 €$ \\
\hline Irlanda & & 2 & $12,68 €$ & & & & 2 & $29,59 €$ & & & 44 & $13,01 €$ & & & & & & & 48 & $29,59 €$ \\
\hline Polónia & & 547 & $19,02 €$ & & 85 & $6,34 €$ & 547 & $44,39 €$ & 85 & $14,80 €$ & & & & & & & & & 1264 & $44,39 €$ \\
\hline Portugal & & 736 & $19,02 €$ & & 68 & $6,34 €$ & 736 & $44,39 €$ & 68 & $14,80 €$ & 12009 & $238,21 €$ & 104 & $6,50 €$ & 160 & $39,02 €$ & 12 & $6,50 €$ & 13893 & $238,21 €$ \\
\hline Suíça & & 32 & $12,68 €$ & & & & 32 & $29,59 €$ & & & 102 & $13,01 €$ & & & & & & & 166 & $29,59 €$ \\
\hline UK & & 575 & $19,02 €$ & & 71 & $6,34 €$ & 575 & $44,39 €$ & 71 & $14,80 €$ & 483 & $26,02 €$ & 2 & $6,50 €$ & 6 & $26,02 €$ & & & 1783 & $44,39 €$ \\
\hline Total Geral & & 5642 & $19,02 €$ & & 374 & $6,34 €$ & 5652 & $110,57 €$ & 374 & $14,80 €$ & \begin{tabular}{|l|}
18374 \\
\end{tabular} & $243,25 €$ & 255 & $6,50 €$ & 223 & $39,02 €$ & 12 & $6,50 €$ & 30906 & $243,25 €$ \\
\hline Data & & & & & $7 x$ & Consu & & $\sqrt{x}$ & Naciona & ade & $z_{x}$ & & & & & & & & & \\
\hline set - dez 2014 & & & & & MESES - & AI BE & AS ADI & LTO... & África & & ^ & & & & & & & & & \\
\hline 2014 & & & & & & AI BE & DASCPI & & Alem & & & & & & & & & & & \\
\hline JUN JUL & AGO & SET & OUT & Nov & DEZ & & & & & & & & & & & & & & & \\
\hline
\end{tabular}

Fonte: Elaboração própria.

Em relação ao suplemento de PC (Pensão Completa), que engloba pequenoalmoço, almoço e jantar, com exceção das bebidas, é interessante notar que nenhum dos países demonstra predileção pelo mesmo. Tal resulta pelo facto da PC ser $16 €$ mais caro do que a MP, mas a diferença residir apenas na inclusão dos almoços, cujo número diário era bastante reduzido em relação aos jantares na unidade hoteleira. Quanto ao valor máximo de consumos realizados por estadia, é curioso verificar que os germânicos $(243,25 €)$ 
têm um plafond superior ao dos portugueses $(238,21 €)$ no regime de MP adulto, muito embora tenham consumido menos $37,86 \%$ do que os turistas portugueses por intermédio deste suplemento.

Por último, é igualmente relevante mencionar que não é possível precisar a quantidade de consumos através do suplemento de APA, visto que, por exemplo, vários clientes de PC poderão ter consumido bebidas num dos bares ou alguns hóspedes de MP poderão ter almoçado num dos restaurantes, o que não é registado como esse suplemento no POS dos estabelecimentos de restauração, uma vez que não estão incluídos no mesmo.

\section{CONSIDERAÇÕES FINAIS}

O ramo da hotelaria necessita progressivamente de saber gerir a imprevisibilidade. Quanto mais previsível o negócio se tornar, maior controle a direção das unidades hoteleiras detém sobre as finanças das instituições. Para combater essa imprevisibilidade, a melhor solução é conseguir controlar o melhor possível essas preferências dos hóspedes, que, com bastante frequência, se tornam um hábito e, por isso mesmo, inalteráveis.

O estudo pretende servir de contributo para o ramo da hotelaria em geral. Esta análise mais aprofundada das preferências dos consumos, tipologias de quarto, regimes de alojamento, agências de viagem, assim como da estatística univariada das despesas com o alojamento e os consumos efetuados no hotel, vem conferir mais detalhe e rigor às previsões de vendas, consumos e ocupação da unidade. É particularmente importante para os setores do Economato, da Receção e da Direção, porque permite, por exemplo, elaborar uma previsão mais precisa das encomendas a realizar, do tipo de ocupação do hotel e das receitas associadas aos consumos consoante o período do ano. Com estas previsões, é possível reduzir/otimizar os custos da unidade, sobretudo nas encomendas de stock.

Por outro lado, o hotel fica com uma perceção ainda maior acerca dos segmentos de mercado que já consegue atingir com relativa facilidade e daqueles em que deveria apostar com maior afinco. Por exemplo, o mercado escandinavo, onde se incluem Dinamarca, Noruega, Suécia e Finlândia, embora 
já tenham representado 0,88\% do número total de hóspedes em 2014, podiam obter uma aposta ainda mais forte durante os meses mais fracos da época baixa, como janeiro e novembro, de forma a conseguir gerar mais receitas.

O estudo pretende demonstrar a importância do sistema de $B I$, do $D W$ e da Modelação Multidimensional para a análise dos inúmeros dados que constituem a realidade comercial de uma unidade hoteleira. Esta análise visa conferir maior rigor, previsibilidade e segurança financeira aos negócios, colmatando as lacunas existentes na disponibilização de informação com maior granularidade pelos PMS, que permitam auxiliar o processo de tomada de decisão e de previsão nas unidades hoteleiras.

Por fim, de referir que o estudo apresenta algumas limitações que se prendem com a utilização de dados relativos apenas a um ano civil (2014) e que seria importante alargar a base temporal no sentido de obter tendências nos consumos dos clientes, no facto de se circunscrever a apenas uma unidade hoteleira da cadeia, e a necessidade de definir KPI (Key Performance Indicators) que permitam a medição, a comparação com outras unidades e a verificação do nível de desempenho e sucesso no que concerne aos consumos dos seus clientes.

REFERÊNCIAS

Berry, M. J., \& Linoff, G. S. (2000). Mastering Data Mining: The Art and Science of Customer Relationship Management. . United States of America: John Wiley and Sons, Inc.

Chaudhuri, S., Dayal, U., \& Narasayya, V. (2011). An overview of business intelligence technology. Communications of the ACM, 54(8), 88-98.

Chen, H., Chiang, R., \& Storey, V. (2012). Business Intelligence and Analytics: From Big Data to Big Impact. MIS Quarterly, 36(4) , 1165-1188.

Curcio, T. (27 de Abril de 2011). O conceito de Business Intelligence. Obtido em 15 de Setembro de 2015, de Revista PC World: http://www.tiagocurcio.com/o-conceito-debusiness-intelligence/

Han, J., Kamber, M., \& Pei, J. (2012). Data Mining: Concepts and Techniques (3ª ed.). Waltham, USA: Morgan Kaufmann Publishers.

Inmon, W. H. (2002). Building the Warehouse ( $3^{\mathrm{a}}$ ed.). United States of America: John Wiley \& Sons, Inc. 
Kimball, R., \& Ross, M. (2013). The Data Warehouse Toolkit (3a ed.). Indianapolis, EUA: John Wiley \& Sons, Inc.

Moody, D. L., \& Kortink, M. A. (2003). From ER Models to Dimensional Models: Bridging the Gap between OLTP and OLAP Design, Part I. Business Intelligence Journal, 7-24.

Nardi, A. R. (4 de Outubro de 2007). Fundamentos e Modelagem de Bancos de Dados Multidimensionais. Obtido em 30 de Setembro de 2015, de Microsoft Brasil: https://msdn. microsoft.com/pt-br/library/cc518031.aspx

Oliveira, R. (2010). Framework de Business Intelligence para o Setor Elétrico Português. ISCTEIUL: Tese de Mestrado em Engenharia Informática.

Rodrigues, A. V., \& Ferreira, C. F. ([s.d.]). An Overview of Data Warehousing and OLAP Technology. (U. d. Porto, Ed.) Porto.

Santos, M. Y., \& Ramos, I. (2006). Business Intelligence - Tecnologias da Informação na Gestão do Conhecimento. Lisboa: FCA - Editora de Informática, Lda.

Turban, E., Sharda, R., \& Delen, D. (2011). Decision Support and Business Intelligence Systems (9th ed. ed.). Upper Saddle River, New Jersey, USA: Pearson Education.

\section{CONTRIBUIÇÃO DOS AUTORES NA CONSTRUÇÃO DO ARTIGO}

GUERREIRO: Revisão teórica, modelação dos dados, análise de conteúdo e conclusões.

CORREIA: Revisão teórica, modelação dos dados, análise de conteúdo e conclusões.

SOUSA: Revisão teórica, modelação dos dados, análise de conteúdo e conclusões. 